\title{
Metal-to-metal charge transfer between dopant and host ions: Photoconductivity of $\mathrm{Yb}$-doped $\mathrm{CaF}_{2}$ and $\mathrm{SrF}_{2}$ crystals
}

\author{
Zoila Barandiarán ${ }^{1,2, a)}$ and Luis Seijo ${ }^{1,2}$ \\ ${ }^{1}$ Departamento de Química, Universidad Autónoma de Madrid, 28049 Madrid, Spain \\ ${ }^{2}$ Instituto Universitario de Ciencia de Materiales Nicolás Cabrera and Condensed Matter Physics Center \\ (IFIMAC), Universidad Autónoma de Madrid, 28049 Madrid, Spain
}

(Received 21 July 2015; accepted 23 September 2015; published online 9 October 2015)

\begin{abstract}
Dopant-to-host electron transfer is calculated using ab initio wavefunction-based embedded cluster methods for $\mathrm{Yb} / \mathrm{Ca}$ pairs in $\mathrm{CaF}_{2}$ and $\mathrm{Yb} / \mathrm{Sr}$ pairs in $\mathrm{SrF}_{2}$ crystals to investigate the mechanism of photoconductivity. The results show that, in these crystals, dopant-to-host electron transfer is a two-photon process mediated by the $4 f^{N-1} 5 d$ excited states of $\mathrm{Yb}^{2+}$ : these are reached by the first photon excitation; then, they absorb the second photon, which provokes the $\mathrm{Yb}^{2+}+\mathrm{Ca}^{2+}$ $\left(\mathrm{Sr}^{2+}\right) \rightarrow \mathrm{Yb}^{3+}+\mathrm{Ca}^{+}\left(\mathrm{Sr}^{+}\right)$electron phototransfer. This mechanism applies to all the observed $\mathrm{Yb}^{2+} 4 f-5 d$ absorption bands with the exception of the first one: Electron transfer cannot occur at the first band wavelengths in $\mathrm{CaF}_{2}: \mathrm{Yb}^{2+}$ because the $\mathrm{Yb}^{3+}-\mathrm{Ca}^{+}$states are not reached by the two-photon absorption. In contrast, $\mathrm{Yb}$-to-host electron transfer is possible in $\mathrm{SrF}_{2}: \mathrm{Yb}^{2+}$ at the wavelengths of the first $4 f-5 d$ absorption band, but the mechanism is different from that described above: first, the twophoton excitation process occurs within the $\mathrm{Yb}^{2+}$ active center, then, non-radiative $\mathrm{Yb}$-to-Sr electron transfer can occur. All of these features allow to interpret consistently available photoconductivity experiments in these materials, including the modulation of the photoconductivity by the absorption spectrum, the differences in photoconductivity thresholds observed in both hosts, and the peculiar photosensitivity observed in the $\mathrm{SrF}_{2}$ host, associated with the lowest $4 f-5 d$ band. (C) 2015 AIP Publishing LLC. [http://dx.doi.org/10.1063/1.4932388]
\end{abstract}

\section{INTRODUCTION}

The dense multiplet structure of the excited states of lanthanide ions associated with their $4 f^{N}$ and $4 f^{N-1} 5 d$ openshell configurations $(N=1-14)$, and their redox behaviour, which allows them to adopt several stable valences, have granted them a prominent role as activators of host crystals useful in the fields of solid state lighting, lasers, fiber amplifiers, and medical imaging devices, among others. ${ }^{1-4}$ In this context, photoinduced electron and energy transfer from a lanthanide dopant ion to the host and vice versa are frequent and basic phenomena which may alter the activator efficiency and pose the difficult question of merging, in a well defined and unique energy diagram, the multiplet level structure of the dopant and the band structure of the host, under mutual influence. Photoconductivity in lanthanide-activated insulators is one of such phenomena, involving photoinduced dopant-tohost electron transfer.

Electron transfer between two metal centers differing only in their valence (i.e., intervalence charge transfer, $\mathrm{IVCT}^{5}$ ) or between two metal centers of different elements (i.e., metalto-metal charge transfer, $\mathrm{MMCT}^{5}$ ) is at the heart of many important processes in geology, biology, chemistry, and material science. ${ }^{6-11}$ Although most of the research effort related with charge transfer in mixed-valence materials has been focused on the kinetics of electron transfer and most of the

\footnotetext{
a) Author to whom correspondence should be addressed. Electronic mail: zoila.barandiaran@uam.es
}

systems involve transition metals, ${ }^{6-11}$ significant contributions in lanthanide-based materials can be found which suggest that photoinduced IVCT and MMCT processes are similarly frequent and are relevant to the optical properties of lanthanide activated materials. ${ }^{12}$ Some representative examples follow: IVCT absorptions have been reported in $\mathrm{Eu}^{2+}-\mathrm{Eu}^{3+}$ mixedvalence $\mathrm{Na}_{5} \mathrm{Eu}_{7} \mathrm{Cl}_{22}$ crystals (Ref. 13) and in $\mathrm{Ce}^{3+}$ activated $\mathrm{LaPO}_{4}$ (Ref. 14). Ultraviolet to greenish-blue or to red conversion in $\mathrm{Pr}^{3+}$-doped $\mathrm{CaTiO}_{3}$ and $\mathrm{CaZrO}_{3}$ crystals is also related with electron transfer within $\mathrm{Pr}^{3+}-\mathrm{Pr}^{4+}$ pairs (Ref. 15). The long-known anomalous luminescences of $\mathrm{Ce}^{3+}$ in elpasolites and $\mathrm{Yb}^{2+}$ in fluorites have been identified as IVCT luminescences. ${ }^{16,17}$ Reversible phototransfer of electrons between divalent and trivalent rare-earth ions involving $\mathrm{Eu}^{2+}-\mathrm{Sm}^{3+}$ pairs in $\mathrm{CaF}_{2}, \mathrm{Eu}^{2+}+\mathrm{Sm}^{3+} \underset{\mathrm{h} v^{\prime}}{\stackrel{\mathrm{h} v}{\rightleftharpoons}} \mathrm{Eu}^{3+}+\mathrm{Sm}^{2+}\left(v \neq v^{\prime}\right)$, was very early identified. ${ }^{18}$ The blue to near-infrared conversion in $\mathrm{Ce}^{3+}, \mathrm{Yb}^{3+}$-codoped YAG (Ref. 19), which can be considered a prototypical energy transfer between optically active centers has been found to involve a MMCT Ce $\mathrm{Ce}^{4+}-\mathrm{Yb}^{2+}$ state. $^{20}$

The photoconductivity and $4 f^{14} \rightarrow 4 f^{13} 5 d$ absorption spectra of $\mathrm{Yb}^{2+}$-doped $\mathrm{CaF}_{2}$ and $\mathrm{SrF}_{2}$ have been measured and compared in Ref. 21. The profiles of the two spectra of the same material are very similar (cf. Figs. 7 and 8 in Ref. 21) and this is so in both materials. This suggests the involvement of $4 f^{13} 5 d$ excited states of the $\mathrm{Yb}^{2+}$ activator in the electron transfer to the hosts. In particular, no photocurrent is detected in the spectral regions where the systems do not or only weakly absorb, which indicates that direct photoionization from the doped crystal 
ground state does not occur. Besides these common facts, some interesting host specific features have been reported ${ }^{21}$ : Whereas the onset of photoconductivity coincides with the onset of the first $4 f-5 d$ absorption band in $\mathrm{SrF}_{2}$, it only appears as the second $4 f-5 d$ absorption band begins in $\mathrm{CaF}_{2}$. Also peculiar is the photosensitivity (which is proportional to the photoconductivity per absorbed photon) in $\mathrm{Yb}^{2+}$-doped $\mathrm{SrF}_{2}$ at low or high excitation energy. All of these characteristics have been interpreted as manifestations that all the $4 f^{13} 5 d$ states of $\mathrm{Yb}^{2+}$ in $\mathrm{SrF}_{2}$ and all but the lowest in energy in $\mathrm{CaF}_{2}$ lie in the conduction band, and the coupling of the $4 f^{13} 5 d$ states with the conduction band is weaker for the low energy than for the high energy states in $\mathrm{SrF}_{2}: \mathrm{Yb}^{2+} \cdot{ }^{21}$ As we will see, this paper provides a different interpretation.

The goal of this paper is to try to understand the relationship between photoconductivity and absorption spectra by calculating the,

$$
\mathrm{Yb}^{2+}+\mathrm{Ca}^{2+}\left(\mathrm{Sr}^{2+}\right) \rightarrow \mathrm{Yb}^{3+}+\mathrm{Ca}^{+}\left(\mathrm{Sr}^{+}\right)
$$

MMCT diabatic potential energy surfaces of the ground and excited states of the $\mathrm{Yb} / \mathrm{Ca}$ and $\mathrm{Yb} / \mathrm{Sr}$ pairs in $\mathrm{CaF}_{2}$ and $\mathrm{SrF}_{2}$, respectively, and the MMCT configuration coordinate diagrams for the electron transfer reactions. The diabatic potential energy surfaces of the ground and excited states of dopanthost ion pairs are calculated using the potential energy surfaces obtained from independent $\mathrm{Yb}^{2+}, \mathrm{Ca}^{2+}\left(\mathrm{Sr}^{2+}\right), \mathrm{Yb}^{3+}$, and $\mathrm{Ca}^{+}\left(\mathrm{Sr}^{+}\right)$embedded cluster calculations as building blocks for the photoinduced electron transfer reactions $\mathrm{Yb}^{2+}+\mathrm{Ca}^{2+}\left(\mathrm{Sr}^{2+}\right)$ $\rightarrow \mathrm{Yb}^{3+}+\mathrm{Ca}^{+}\left(\mathrm{Sr}^{+}\right)$. As shown in previous works, ${ }^{16,17,20}$ the diabatic approximation, which neglects the electronic coupling between $\mathrm{Yb}^{2+}-\mathrm{Ca}^{2+}\left(\mathrm{Sr}^{2+}\right)$ and $\mathrm{Yb}^{3+}-\mathrm{Ca}^{+}\left(\mathrm{Sr}^{+}\right)$states, should be acceptable because the photoinduced electron transfer transition energies rather than the kinetics of the electron transfer are the target. The electronic structure of the ground and excited states of the independent embedded clusters (which are formed by the metal ions and the fluoride ligands) are calculated using the relativistic second-order Douglas-KrollHess Hamiltonian, ${ }^{22-24}$ complete/restricted active space selfconsistent field (CASSCF/RASSCF) ${ }^{25-29}$ and multistate second order perturbation methods (ms-CAS/RASPT2) ${ }^{29-33}$ to account for non-dynamic and dynamic correlations of the valence electrons of the clusters, respectively, restricted active space state interaction RASSI-SO method to include spinorbit coupling, ${ }^{34}$ and $a b$ initio model potentials (AIMP) to incorporate the effects of the embedding hosts. ${ }^{35,36}$

The results of the calculations indicate that the tight relationship between the $\mathrm{Yb}^{2+} 4 f-5 d$ absorptions and the photoconductivity of $\mathrm{Yb}^{2+}$-doped $\mathrm{CaF}_{2}$ and $\mathrm{SrF}_{2}$ is due to twophoton processes mediated by the $4 f^{N-1} 5 d$ excited states of $\mathrm{Yb}^{2+}$, which provoke the $\mathrm{Yb}^{2+}+\mathrm{Ca}^{2+}\left(\mathrm{Sr}^{2+}\right) \rightarrow \mathrm{Yb}^{3+}+\mathrm{Ca}^{+}$ $\left(\mathrm{Sr}^{+}\right)$phototransfers.

This paper is organized as follows. In Sec. II, we describe how the MMCT diabatic potential energy surfaces and how the MMCT configuration coordinate diagrams are built from $a b$ initio calculations on independent single active ion embedded cluster calculations. In Sec. III, we describe the results of the calculations and the mechanism they suggest for the photocon- ductivity in the materials studied. The conclusions are summarized in Sec. IV.

\section{MMCT CONFIGURATION COORDINATE DIAGRAMS FOR DOPANT-TO-HOST ELECTRON TRANSFER}

In this section, we describe how diabatic potential energy surfaces and configuration coordinate diagrams for MMCT reactions between ground and excited states of metal-metal pairs can be computed from $a b$ initio wavefunction-based quantum mechanical methods. Complementary to this approach is the parametric formulation given in Ref. 20, where IVCT and MMCT configuration coordinate diagrams can be obtained from experimental data, when available.

\section{A. Diabatic potential energy surfaces for MMCT reaction}

\section{Dopant-to-host charge transfer reaction}

The photoinduced electron transfer from the $\mathrm{Yb}^{2+}$ lanthanide dopant ion to the $\mathrm{CaF}_{2}$ (or $\mathrm{SrF}_{2}$ ) host,

$$
\mathrm{Yb}^{2+}+\mathrm{Ca}^{2+}\left(\mathrm{Sr}^{2+}\right) \rightarrow \mathrm{Yb}^{3+}+\mathrm{Ca}^{+}\left(\mathrm{Sr}^{+}\right),
$$

can be studied by calculating the electronic structure of the donor $(D)$-acceptor $(A)$ pair $\left(\mathrm{Yb}^{2+}-\mathrm{Ca}^{2+}\right.$ or $\left.\mathrm{Yb}^{2+}-\mathrm{Sr}^{2+}\right)$ before and after the electron transfer,

$$
D_{i} A_{j} \rightarrow D_{k}^{+} A_{l}^{-},
$$

where the initial and final electronic states of the metal-metal pair have been indicated as subscripts. This notation reflects a correspondence of the pair states with states of the $D, A, D^{+}$, and $A^{-}$local defects, which, in the present case, are the ground and excited states of the $\left(\mathrm{YbF}_{8}\right)^{6-},\left(\mathrm{CaF}_{8}\right)^{6-}\left[\right.$ or $\left(\mathrm{SrF}_{8}\right)^{6-}$, $\left(\mathrm{YbF}_{8}\right)^{5-}$, and $\left(\mathrm{CaF}_{8}\right)^{7-}\left[\right.$ or $\left.\left(\mathrm{SrF}_{8}\right)^{7-}\right]$ embedded clusters.

\section{Diabatic states of dopant-host ion pairs}

In order to calculate the potential energy surfaces of the $D_{i} A_{j}$ and $D_{k}^{+} A_{l}^{-}$states, we will adapt the IVCT approach of Refs. 16 and 17 to the present MMCT case. For this, we should take into account that $D$ and $A$ differ only in oxidation state in the IVCT case, hence the $A D$ pair obtained after IVCT corresponds to the $D^{+} A^{-}$pair after MMCT. Hence the diabatic wavefunctions for the MMCT $D_{i} A_{j}$ and $D_{k}^{+} A_{l}^{-}$states can be expressed in terms of the following generalized antisymmetric product functions: ${ }^{37}$

$\Psi\left(D_{i} A_{j}\right)=M \hat{A}\left(\Phi_{D i} \Phi_{A j}\right) ; \quad \Psi\left(D_{k}^{+} A_{l}^{-}\right)=M \hat{A}\left(\Phi_{D_{k}^{+}} \Phi_{A_{l}^{-}}\right)$,

where the group wavefunctions $\Phi_{D_{i}}, \Phi_{A_{j}}, \Phi_{D_{k}^{+}}$, and $\Phi_{A_{l}^{-}}$correspond to the ground and excited states of the $D, A, D^{+}$, and $A^{-}$ moieties of the metal-metal pair ( $M$ is a normalization constant and $\hat{A}$ is the inter-group antisymmetrization operator). ${ }^{37}$

The corresponding diabatic potential energy surfaces $E_{D_{i} A_{j}}^{\mathrm{diab}}$ and $E_{D_{k}^{+} A_{l}^{-}}^{\mathrm{diab}}$ are calculated assuming they are the expected values of the fixed nuclei Hamiltonian of the embedded metal-metal pair $\hat{H}: E_{D_{i} A_{j}}^{\text {diab }}=\left\langle\Psi\left(D_{i} A_{j}\right)|\hat{H}| \Psi\left(D_{i} A_{j}\right)\right\rangle, E_{D_{k}^{+} A_{l}^{-}}^{\text {diab }}$ 
$=\left\langle\Psi\left(D_{k}^{+} A_{l}^{-}\right)|\hat{H}| \Psi\left(D_{k}^{+} A_{l}^{-}\right)\right\rangle$, and that the electronic coupling between the $D_{i} A_{j}$ and $D_{k}^{+} A_{l}^{-}$states, $V_{D_{i} A_{j}, D_{k}^{+} A_{l}^{-}}^{\text {diab }}=\left\langle\Psi\left(D_{i} A_{j}\right)|\hat{H}|\right.$ $\left.\Psi\left(D_{k}^{+} A_{l}^{-}\right)\right\rangle$, can be neglected. This is the diabatic approximation. The coupling terms are very important for the kinetics of the electron transfer, particularly, when the reaction is thermally induced and the transition state is in the reaction path. However, the goal here is the photoinduced electron transfer that occurs away from the configurations where MMCT states cross. In these regions, the effects of the couplings can be expected to be very attenuated, so that the diabatic approximation can lead to stable and meaningful results which allow to understand, at a first order level, the radiative and nonradiative processes involved. This ability has been shown in the theoretical study of IVCT luminescence and its interplay with regular luminescence in $\mathrm{Ce}^{3+} / \mathrm{Ce}^{4+}$ and $\mathrm{Yb}^{2+} / \mathrm{Yb}^{3+}$ mixedvalence pairs in elpasolites and fluorites. ${ }^{16,17}$

Given that non-totally symmetric vibrational modes do not produce horizontal offsets between different potential energy surfaces, the shape of the electronic spectra is dominated by the totally symmetric modes in general. Hence we will assume the diabatic potential energy surfaces depend parametrically on the donor $\left(Q_{D}\right)$ and acceptor $\left(Q_{A}\right)$ local breathing modes only: $E_{D_{i} A_{j}}^{\text {diab }}\left(Q_{D}, Q_{A}\right), E_{D_{k}^{+} A_{l}^{-}}^{\text {diab }}\left(Q_{D}, Q_{A}\right)$. In our case, they will depend on the metal-ligand distances $d_{D}(\mathrm{Yb}-\mathrm{F})$ and $d_{A}(\mathrm{Ca}-\mathrm{F}$ or Sr-F): $E_{D_{i} A_{j}}^{\text {diab }}\left(d_{D}, d_{A}\right)$ and $E_{D_{k}^{+} A_{l}^{\text {diab }}}^{(}\left(d_{D}, d_{A}\right)$ given that $Q_{D}$ and $Q_{A}$ are the symmetric stretch of the $\mathrm{YbF}_{8}$ and $\mathrm{CaF}_{8}\left(\mathrm{SrF}_{8}\right)$ cubic moieties, respectively. (Note that $d_{D}$ and $d_{A}$ correspond to $d_{L}$ and $d_{R}$, respectively, in Refs. 16 and 17.) Assuming also the independent-embedded cluster approach proposed in Refs. 16 and $17, E_{D_{i} A_{j}}^{\mathrm{diab}}\left(d_{D}, d_{A}\right)$, and similarly $E_{D_{k}^{+} A_{l}^{-}}^{\text {diab }}\left(d_{D}, d_{A}\right)$, can be calculated using Eqs. (1)-(3) of Ref. 17, so that the independent embedded-cluster energy curves in Eq. (2), $E_{D_{i}}^{(i e c)}\left(d_{D}\right)$ and $E_{A_{j}}^{(i e c)}\left(d_{A}\right)$, and $E_{D_{k}^{+}}^{(i e c)}\left(d_{D}\right)$ and $E_{A_{l}^{-}}^{(i e c)}\left(d_{A}\right)$, are calculated as described in Sec. II A 3 of this paper.

In contrast with the IVCT case, ${ }^{16,17}$ which is a homonuclear MMCT leading to $E_{D_{0} A_{0}, e}^{\text {diab }}=E_{D_{0}^{+} A_{0}^{-}, e}^{\text {diab }}$, the relaxed ground states of the metal-metal pair before and after electron transfer are shifted in energy in the MMCT case: $E_{D_{0} A_{0}, e}^{\text {diab }} \neq E_{D_{0}^{+} A_{0}^{-}, e}^{\text {diab }}$ Using Eqs. (2) and (3) of Ref. 17, the vertical shift is found to depend on the adiabatic (minimum-to-minimum) ionization potential of the $D$ moiety and the negative of the electron affinity of $A$ in the host, as follows:

$$
\begin{aligned}
E_{D_{0}^{+} A_{0}^{-}, e}^{\text {diab }}-E_{D_{0} A_{0}, e}^{\text {diab }}= & I P_{D}-E A_{A} \\
& -\left[\left(q_{D}-q_{M}\right)-\left(q_{A}-q_{M}\right)+1\right] e^{2} / d_{D A}, \\
I P_{D}= & E_{D_{0}^{+}}^{(i e c)}\left(d_{e D_{0}^{+}}\right)-E_{D_{0}}^{(i e c)}\left(d_{e D_{0}}\right), \\
E A_{A}= & E_{A_{0}}^{(i e c)}\left(d_{e A_{0}}\right)-E_{A_{0}^{-}}^{(i e c)}\left(d_{e A_{0}^{-}}\right) .
\end{aligned}
$$

The point charge term in Eq. (2) depends on the defect charges of the donor $\left(q_{D}-q_{M}\right)$ and the acceptor $\left(q_{A}-q_{M}\right)$. In this case, it leads to $-1 / d_{D A}$, which is the electrostatic attraction between the hole created in the $\mathrm{Yb}^{2+}$ donor and the electron transferred to the $\mathrm{Ca}^{2+}\left(\mathrm{Sr}^{2+}\right)$ acceptor host ions in the MMCT process. This term brings the dependence on the distance between the donor and acceptor ions in the pair.

All MMCT potential energy curves will be referred to the energy of the relaxed $D A$ ground state, which will be set to zero: $E_{D_{0} A_{0}, e}^{\mathrm{dia}}=0$. Two diabatic potential energy surfaces for the $\mathrm{Yb} / \mathrm{Ca}$ pairs in $\mathrm{CaF}_{2}$ have been plotted in the left panel of Fig. 1 projecting them in the $\mathrm{Q}_{\mathrm{D}}, \mathrm{Q}_{\mathrm{A}}$ plane (or the $\mathrm{d}_{\mathrm{D}}, \mathrm{d}_{\mathrm{A}}$ plane): the diabatic potential energy surface for the ground state of the $D A \mathrm{Yb}^{2+}-\mathrm{Ca}^{2+}$ pairs $E_{D_{0} A_{0}, e}^{\text {diab }}\left(Q_{D}, Q_{A}\right)$ (violet isolines) and for the first excited state of the $D^{+} A^{-} \mathrm{Yb}^{3+}-\mathrm{Ca}^{+}$pairs $E_{D_{0}^{+} A_{1}^{-}, e}^{\text {diab }}\left(Q_{D}, Q_{A}\right)$ (red isolines).

\section{Independent embedded cluster calculations}

We describe here the independent embedded cluster calculations performed to provide the $E_{D_{i}}^{(i e c)}\left(d_{D}\right), E_{A_{j}}^{(i e c)}\left(d_{A}\right), E_{D_{k}^{+}}^{(i e c)}$ $\left(d_{D}\right)$, and $E_{A_{l}^{-}}^{(i e c)}\left(d_{A}\right)$ energy curves needed to build the diabatic potential energy surfaces $E_{D_{i} A_{j}}^{\text {diab }}\left(d_{D}, d_{A}\right)$ and $E_{D_{k}^{+} A_{l}^{-}}^{\text {diab }}\left(d_{D}, d_{A}\right)$ using Eq. (2) of Ref. 17. As mentioned above, $D, D^{+}, A$, and $A^{-}$ refer to the cubic $\left(\mathrm{YbF}_{8}\right)^{6-},\left(\mathrm{YbF}_{8}\right)^{5-},\left(\mathrm{CaF}_{8}\right)^{6-}\left[\mathrm{or}\left(\mathrm{SrF}_{8}\right)^{6-}\right]$, and $\left(\mathrm{CaF}_{8}\right)^{7-}$ [or $\left.\left(\mathrm{SrF}_{8}\right)^{7-}\right]$ clusters embedded in the $\mathrm{CaF}_{2}$ (or $\mathrm{SrF}_{2}$ ) crystals, respectively.

All the embedded cluster calculations have been done using the relativistic second-order Douglas-Kroll-Hess Hamiltonian ${ }^{22-24}$ for the cubic clusters defined in the previous paragraph including all their electrons. The one-electron quantum mechanical AIMP embedding operators ${ }^{35,36}$ have been added to the cluster Hamiltonian to account for the $\mathrm{CaF}_{2}$ or $\mathrm{SrF}_{2}$ surrounding crystal (see Ref. 17 for details). Using quadruple-zeta plus polarization contractions of the relativistic atomic natural orbital basis sets (ANO-RCC) ${ }^{38-40}-\mathrm{Yb}$ (25s22p15d11f4g2h) [9s8p5d4f3g2h], Ca (20s16p6d4f2g) [8s5p4d2f], Sr (23s19p12d4f2g) [8s7p4d2f], F (14s9p4d3f2g) [5s4p3d]-, supplemented with second-neighbor orthogonalization functions (the outermost occupied orbitals of $\mathrm{Ca}$ (20s15p) [1s1p], and $\mathrm{Sr}(23 \mathrm{~s} 19 \mathrm{p})$ [1s1p]), which are used to fulfil cluster-environment orthogonality, ${ }^{35,36}$ and 5 s-type Gaussian functions at the interstices nearest to the $\mathrm{YbF}_{8}$ clusters, multireference wavefunctions and energies were obtained along three steps of the calculations which, successively, incorporate (i) bonding and non-dynamic correlation, including radial correlation in the $\mathrm{Yb} 4 f$ shell, ${ }^{41}$ by means of CASSCF/RASSCF, ${ }^{25-29}$ (ii) dynamic correlation of all valence electrons of the clusters, by means of the multi-state secondorder perturbation method, ms-CAS/RASPT $2,{ }^{29-33}$ and (iii) spin-orbit coupling through the restricted active space state interaction RASSI-SO method. ${ }^{34}$

More details of the calculations on the $\left(\mathrm{YbF}_{8}\right)^{6-}(D)$ and $\left(\mathrm{YbF}_{8}\right)^{5-}\left(D^{+}\right)$embedded clusters can be found in Section II B of Ref. 17, together with the energy curves and descriptions of the electronic structure of the ground and excited states of the $\mathrm{Yb}^{2+}$ and $\mathrm{Yb}^{3+}$ active centers. The excited states of $\mathrm{Yb}^{2+}$ in the two fluorites studied here were found to be grouped in four manifolds of impurity states: $4 f^{13}\left({ }^{2} F_{7 / 2}\right) 5 d e_{g}$, $4 f^{13}\left({ }^{2} F_{5 / 2}\right) 5 d e_{g}, 4 f^{13}\left({ }^{2} F_{7 / 2}\right) 5 d t_{2 g}$, and $4 f^{13}\left({ }^{2} F_{5 / 2}\right) 5 d t_{2 g}$, and two of impurity-trapped excitons (YbTE), whose excited electron density extends towards the next interstices in the 


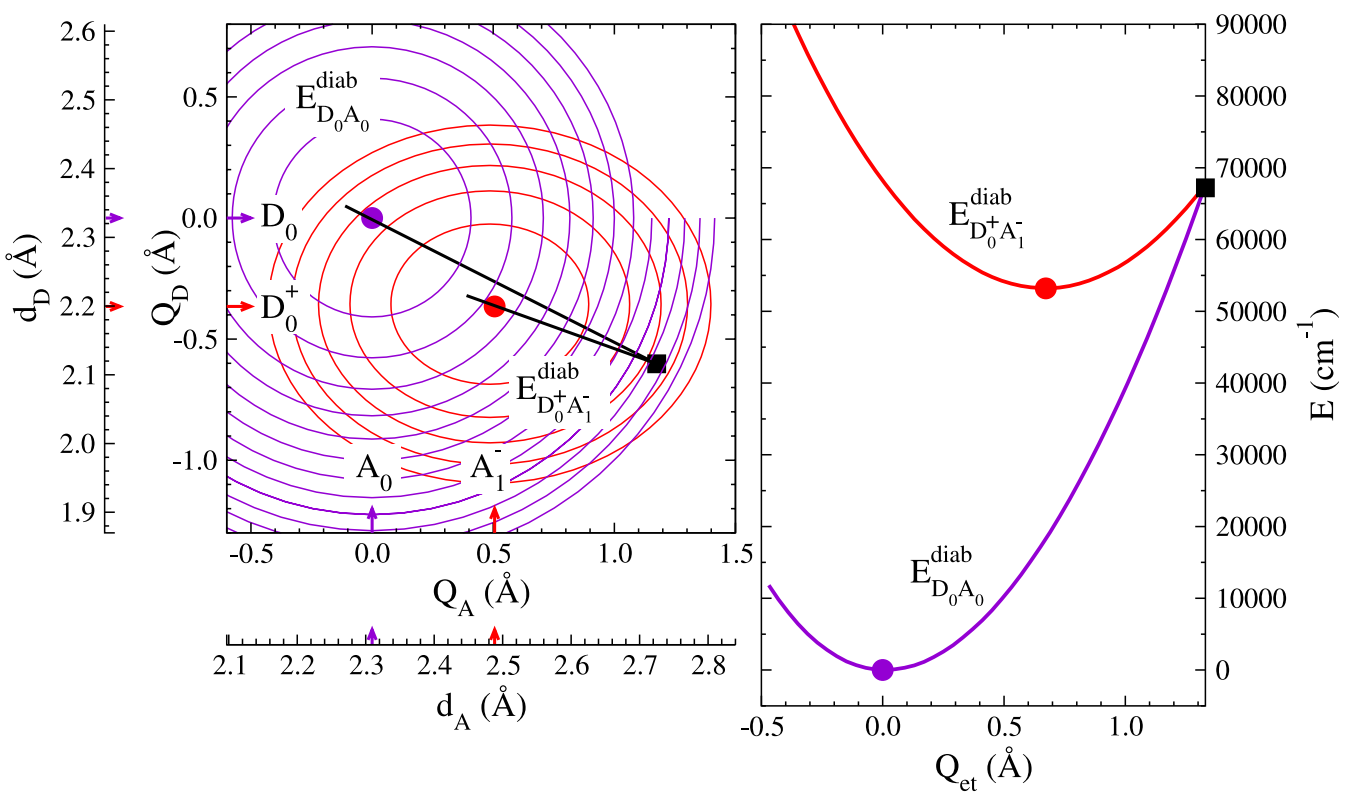

FIG. 1. Electron transfer reaction coordinate chosen for the MMCT energy diagram of $\mathrm{Yb} / \mathrm{Ca}$ in $\mathrm{CaF}_{2} . D, D^{+}, A$, and $A^{-}$stand for $\left(\mathrm{YbF}_{8}\right)^{6-},\left(\mathrm{YbF}_{8}\right)^{5-}$, $\left(\mathrm{CaF}_{8}\right)^{6-}$, and $\left(\mathrm{CaF}_{8}\right)^{7-}$ clusters embedded in $\mathrm{CaF}_{2}$. Left panel: diabatic potential energy surfaces of the ground state of the $D A$ pair, $E_{D_{0} A_{0}}^{\text {diab }}($ violet isolines), and of the first excited state of the $D^{+} A^{-}$pair, $E_{D_{0}^{+} A_{1}^{-}}^{\text {diab }}$ (red isolines), as functions of the breathing vibrational modes of the $\mathrm{YbF}_{8}$ and $\mathrm{CaF}_{8}$ moieties, $Q_{D}$ and $Q_{A}$; the corresponding $\mathrm{Yb}-\mathrm{F}$ and Ca-F distances, $d_{D}$ and $d_{A}$ are also indicated. Their respective minima are shown with full circles and a black full square signals the position of the activated complex. The black straight lines indicate the electron transfer reaction coordinate $Q_{e t}$. Right panel: energies of the two states along the electron transfer reaction coordinate; note that the state of $D A$ is evaluated along the line connecting the violet and black spots in the left panel, whereas the state of $D^{+} A^{-}$is evaluated along the line connecting the black and red spots. The extension of this representation to all states of $D A$ and $D^{+} A^{-}$is shown in Fig. 2.

fluorite structures: $4 f^{13}\left({ }^{2} F_{7 / 2}\right) a_{1 g}^{\mathrm{YbTE}}$ and $4 f^{13}\left({ }^{2} F_{5 / 2}\right) a_{1 g}^{\mathrm{YbTE}}$. These YbTE states are found to interact considerably with states of $4 f^{13}\left({ }^{2} F_{5 / 2}\right) 5 d e_{g}$ and $4 f^{13}\left({ }^{2} F_{7 / 2}\right) 5 d t_{2 g}$ configurations, respectively (cf. Ref. 17).

Analogous embedded cluster calculations have been done in the host ion clusters $\left(\mathrm{CaF}_{8}\right)^{6-}(A)$ and $\left(\mathrm{CaF}_{8}\right)^{7-}\left(A^{-}\right)$and the $\mathrm{Sr}$ analogues: $\left(\mathrm{SrF}_{8}\right)^{6-}$ and $\left(\mathrm{SrF}_{8}\right)^{7-}$, using the $\mathrm{CaF}_{2}$ and $\mathrm{SrF}_{2}$ embedding potentials, respectively, and the basis sets described above for the all electron clusters. Single-reference
CASPT2 calculations on the $\mathrm{Ca}^{2+}$ and $\mathrm{Sr}^{2+}$ closed shell ${ }^{1} A_{1 \mathrm{~g}}$ states were done correlating the 72 valence electrons in the $\mathrm{Ca} 3 s^{2} 3 p^{6}\left(\mathrm{Sr} 4 s^{2} 4 p^{6}\right)$ and $\mathrm{F} 2 s^{2} 2 p^{6}$ shells of the $\left(\mathrm{CaF}_{8}\right)^{6-}$ and $\left(\mathrm{SrF}_{8}\right)^{6-}$ clusters. Analogous single-reference CASPT2 calculations on the $\mathrm{n} s^{1}-^{2} A_{1 \mathrm{~g}},(\mathrm{n}-1) d^{1}-^{2} E_{\mathrm{g}},{ }^{2} T_{2 \mathrm{~g}}$, and $\mathrm{n} p^{1}-^{2} T_{1 u}$ states $(\mathrm{Ca}: \mathrm{n}=4 ; \mathrm{Sr}: \mathrm{n}=5$ ) were done correlating 73 valence electrons of the $\left(\mathrm{CaF}_{8}\right)^{7-}$ and $\left(\mathrm{SrF}_{8}\right)^{7-}$ embedded clusters. The results of the subsequent RASSI-SO calculations are given in Table I. Comparison of the calculated $\mathrm{Ca}-\mathrm{F}$ and $\mathrm{Sr}-\mathrm{F}$ equilibrium

TABLE I. Calculated spectroscopic constants of the cubic embedded clusters $\left(\mathrm{CaF}_{8}\right)^{6-}$ and $\left(\mathrm{CaF}_{8}\right)^{7-}$ in $\mathrm{CaF}_{2}$, and $\left(\mathrm{SrF}_{8}\right)^{6-}$ and $\left(\mathrm{SrF}_{8}\right)^{7-}$ in $\mathrm{SrF}_{2}: \mathrm{Ca}-\mathrm{F}$ and $\mathrm{Sr}-\mathrm{F}$ equilibrium distances $d_{\mathrm{Ca}-\mathrm{F}, e}$ and $d_{\mathrm{Sr}-\mathrm{F}, e}(\AA)$, breathing mode harmonic vibrational frequencies $\omega_{a_{1 g}}\left(\mathrm{~cm}^{-1}\right)$, and minimum-to-minimum transition energies $\mathrm{T}_{e}\left(\mathrm{~cm}^{-1}\right)$. Two sets of $\mathrm{T}_{e}$ are given: one with respect to $n s^{0}{ }^{1} A_{1 \mathrm{~g}}$ and another one with respect to $(\mathrm{n}-1) d^{12} E_{\mathrm{g}}$.

\begin{tabular}{|c|c|c|c|c|c|c|c|}
\hline \multirow{2}{*}{$\begin{array}{l}\text { Main } \\
\text { configuration }^{\mathrm{a}}\end{array}$} & \multirow[b]{2}{*}{ State } & \multicolumn{3}{|c|}{$\mathrm{CaF}_{2}$} & \multicolumn{3}{|c|}{$\mathrm{SrF}_{2}$} \\
\hline & & $d_{\mathrm{Ca}-\mathrm{F}, e^{\mathrm{b}}}$ & $\omega_{a_{1 g}}$ & $\mathrm{~T}_{e}$ & $d_{\mathrm{Sr}-\mathrm{F}, e^{\mathrm{b}}}$ & $\omega_{a_{1 g}}$ & $\mathrm{~T}_{e}$ \\
\hline & & \multicolumn{3}{|c|}{$\mathrm{Ca}^{2+}$} & \multicolumn{3}{|c|}{$\mathrm{Sr}^{2+}$} \\
\hline \multirow[t]{2}{*}{$\mathrm{n} s^{0}$} & $1 A_{1 g}\left({ }^{1} A_{1 g}\right)$ & $2.309(2.366)$ & 403 & 0 & $2.464(2.510)$ & 364 & 0 \\
\hline & & \multicolumn{3}{|c|}{$\mathrm{Ca}^{+}$} & \multicolumn{3}{|c|}{$\mathrm{Sr}^{+}$} \\
\hline$(\mathrm{n}-1) d^{1}$ & $1 \Gamma_{8 g}\left({ }^{2} E_{g}\right)$ & 2.459 & 345 & $\begin{array}{r}73600 \\
0\end{array}$ & 2.635 & 307 & $\begin{array}{r}64700 \\
0\end{array}$ \\
\hline $\mathrm{n} s^{1}$ & $1 \Gamma_{6 g}\left({ }^{2} A_{1 g}\right)$ & 2.488 & 303 & 2300 & 2.655 & 270 & 3800 \\
\hline \multirow[t]{2}{*}{$(\mathrm{n}-1) d^{1}$} & $2 \Gamma_{8 g}\left({ }^{2} T_{2 g}\right)$ & 2.507 & 334 & 18700 & 2.700 & 301 & 19900 \\
\hline & $1 \Gamma_{7 g}\left({ }^{2} T_{2 g}\right)$ & 2.507 & 334 & 18700 & 2.700 & 301 & 20100 \\
\hline \multirow[t]{2}{*}{$\mathrm{n} p^{1}$} & $1 \Gamma_{6 u}\left({ }^{2} T_{1 u}\right)$ & 2.454 & 317 & 23300 & 2.602 & 292 & 21600 \\
\hline & $1 \Gamma_{8 u}\left({ }^{2} T_{1 u}\right)$ & 2.454 & 317 & 23400 & 2.599 & 293 & 22200 \\
\hline
\end{tabular}

${ }^{\mathrm{a}} \mathrm{Ca}: \mathrm{n}=4 ; \mathrm{Sr}: \mathrm{n}=5$.

${ }^{\mathrm{b}}$ Experimental values from the crystal structures from Ref. 46 are given in parentheses. 
distances with those of the experimental crystal structures shows errors of $-0.057 \AA(2.4 \%)$ and $-0.046 \AA(1.8 \%)$, respectively, which can be associated with the embedded cluster approximation used for the perfect hosts, in particular, the limited second-neighbour basis set and the frozen environment approximation, in addition to the limitations inherent to the correlation methods employed.

The program MOLCAS was used for all calculations. ${ }^{42}$ All AIMP data and interstitial basis sets can be found in Ref. 43 .

\section{B. MMCT configuration coordinate diagrams}

MMCT configuration coordinate diagrams result from representing the energies of the states of $D A$ and $D^{+} A^{-}$along electron transfer reaction coordinates. In Sec. II B 1 we define and illustrate the electron transfer reaction coordinate $Q_{e t}$ and in Sec. II B 2 we describe the diagrams for $\mathrm{Yb} / \mathrm{Ca}$ and $\mathrm{Yb} / \mathrm{Sr}$ pairs.

\section{Electron transfer reaction coordinate}

Here, we describe the electron transfer reaction coordinate we use for the MMCT configuration coordinate diagrams. We do it for the $\mathrm{CaF}_{2}$ and obvious changes hold for $\mathrm{SrF}_{2}$. As we indicated above, the diabatic energies of the states of the $D A$ and $D^{+} A^{-}$pairs [we recall that $D, D^{+}, A$, and $A^{-}$stand for $\left(\mathrm{YbF}_{8}\right)^{6-},\left(\mathrm{YbF}_{8}\right)^{5-},\left(\mathrm{CaF}_{8}\right)^{6-}$, and $\left(\mathrm{CaF}_{8}\right)^{7-}$ clusters] are functions of the $Q_{D}$ and $Q_{A}$ breathing modes of the $\mathrm{YbF}_{8}$ and $\mathrm{CaF}_{8}$ moieties. Let us start by defining these modes in terms of $\mathrm{Yb}-\mathrm{F}$ and $\mathrm{Ca}-\mathrm{F}$ bond length increments with respect to the corresponding equilibrium structures of $D\left(\delta_{F_{1}}, \ldots, \delta_{F_{8}}\right)$ and $A\left(\delta_{F_{9}}, \ldots, \delta_{F_{16}}\right)$,

$$
\begin{aligned}
& Q_{D}=\frac{1}{\sqrt{8}}\left(\delta_{F_{1}}+\delta_{F_{2}}+\cdots+\delta_{F_{8}}\right)=\sqrt{8}\left(d_{D}-d_{D e}\right), \\
& Q_{A}=\frac{1}{\sqrt{8}}\left(\delta_{F_{9}}+\delta_{F_{10}}+\cdots+\delta_{F_{16}}\right)=\sqrt{8}\left(d_{A}-d_{A e}\right) .
\end{aligned}
$$

Here, $d_{D}$ and $d_{A}$ stand for the distances $d(\mathrm{Yb}-\mathrm{F})$ and $d(\mathrm{Ca}-\mathrm{F})$, and $d_{D e}$ and $d_{A e}$ for their values at the equilibrium structures of $\left(\mathrm{YbF}_{8}\right)^{6-}$ and $\left(\mathrm{CaF}_{8}\right)^{6-}$ in their ground states. The energies of the states of the $D A$ and $D^{+} A^{-}$around their minima are approximately quadratic in $Q_{D}$ and $Q_{A}$. In the left panel of Fig. 1 we show those of the ground state of $D A, E_{D_{0} A_{0}}^{\text {diab }}\left(Q_{D}, Q_{A}\right)$, and the first excited state of $D^{+} A^{-}, E_{D_{0}^{+} A_{1}^{-}}^{\text {diab }}\left(Q_{D}, Q_{A}\right)$ (which is only slightly above its ground state). In the figure, the lowest energy point of the crossing between the two states is signalled with a full black square. This is the activation complex of the thermal reaction $D_{0} A_{0} \rightarrow a c \rightarrow D_{0}^{+} A_{1}^{-}$and the trajectory that connects the minimum of $E_{D_{0} A_{0}}^{\mathrm{diab}}$ with this activation complex and then continues towards the minimum of $E_{D_{0}^{+} A_{1}^{-}}^{\text {,iab }}$, is the corresponding electron transfer reaction coordinate. Its definition is

$$
Q_{e t}=\frac{1}{\sqrt{1+m^{2}}}\left[\left(Q_{A}-Q_{A_{0}}\right)+m\left(Q_{D}-Q_{D_{0}}\right)\right] .
$$

Note that according to the present definition of $Q_{D}$ and $Q_{A}$ in Eq. (3), $Q_{D_{0}}=0$ and $Q_{A_{0}}=0$, but we prefer to make them explicit here, so that the equations are valid for other choices of reference for $Q_{D}$ and $Q_{A}$. In parametric form, the electron transfer reaction coordinate reads

$$
\left\{\begin{array}{l}
Q_{D}-Q_{D_{0}}=\frac{m}{\sqrt{1+m^{2}}} Q_{e t}, \\
Q_{A}-Q_{A_{0}}=\frac{1}{\sqrt{1+m^{2}}} Q_{e t} .
\end{array}\right.
$$

The values of $m$ are

$$
m=\frac{Q_{D, a c}-Q_{D_{0}}}{Q_{A, a c}-Q_{A_{0}}}
$$

for the $D_{0} A_{0} \rightarrow a c$ part, and

$$
m=\frac{Q_{D_{0}^{+}}-Q_{D, a c}}{Q_{A_{1}^{-}}-Q_{A, a c}},
$$

for the $a c \rightarrow D_{0}^{+} A_{1}^{-}$part, $Q_{D, a c}$ and $Q_{A, a c}$ being the values of $Q_{D}$ and $Q_{A}$ at the activated complex. The trajectory that defines $Q_{e t}$ is indicated in the left panel of Fig. 1. The representation of the energies of all states of $D A$ along the first part of the electron transfer reaction coordinate and of all states of $D^{+} A^{-}$ along the second part, constitutes the MMCT configuration coordinate. In the right panel of Fig. 1, we show only the two states which defined $Q_{e t}$. The present choice of states of $D A$ and $D^{+} A^{-}$for the definition of $Q_{e t}$ is convenient for the discussions in this paper; other choices might be convenient for other purposes.

\section{MMCT configuration coordinate diagrams for $\mathrm{Yb} / \mathrm{Ca}$ and $\mathrm{Yb} / \mathrm{Sr}$ pairs}

In Fig. 2, we present the MMCT configuration coordinate diagram of the $\mathrm{Yb} / \mathrm{Ca}$ pairs in $\mathrm{CaF}_{2}$ which results from using Eq. (2) of Ref. 17 along the ground state electron transfer reaction coordinate defined in Eqs. (5)-(7). The curves whose minima are at or close to $Q_{e t}=0$ correspond to the ground and excited states of the $\mathrm{Yb}^{2+}-\mathrm{Ca}^{2+}$ pair. Given that the $\mathrm{Ca}^{2+}$ moiety contributes only the $4 s^{0}-1 A_{1 \mathrm{~g}}$ electronic state, the $\mathrm{Yb}^{2+}-\mathrm{Ca}^{2+}\left[D_{i}, 4 s^{0}-1 A_{1 \mathrm{~g}}\right]$ curves reveal the $\mathrm{Yb}^{2+}$ structure of manifolds mentioned above, whose main configurations follow (in increasing energy order): $4 f^{14} 1 A_{1 \mathrm{~g}}$, plotted in violet; $4 f^{13}\left({ }^{2} F_{7 / 2}\right) 5 d e_{g}$, and $4 f^{13}\left({ }^{2} F_{5 / 2}\right) 5 d e_{g}$, in blue or in maroon, when the $4 f^{13}\left({ }^{2} F_{5 / 2}\right) 5 d e_{g}$ and $4 f^{13}\left({ }^{2} F_{7 / 2}\right) a_{1 g}^{Y b T E}$ states interact; interacting $4 f^{13}\left({ }^{2} F_{5 / 2}\right) a_{1 g}^{Y b T E}$ and $4 f^{13}\left({ }^{2} F_{7 / 2}\right) 5 d t_{2 g}$, in maroon; and, finally, $4 f^{13}\left({ }^{2} F_{5 / 2}\right) 5 d t_{2 g}$, in green (see Ref. 17 for details). The curves that cross them and show much larger horizontal offsets correspond to the $\mathrm{Yb}^{3+}-\mathrm{Ca}^{+}$states. The combination of the $\mathrm{Yb}^{3+} 4 f^{13}\left({ }^{2} F_{7 / 2}\right)$ and $4 f^{13}\left({ }^{2} F_{5 / 2}\right)$ states with the $3 d e_{g}$ (cyan), $4 s$ (red), $3 d t_{2 g}$ (orange), and $4 p$ (black) states of $\mathrm{Ca}^{+}$is apparent in Fig. 2 (see Ref. 17 and Table I for data on the parent independent embedded clusters). The MMCT configuration coordinate diagram of the $\mathrm{Yb}^{2+} / \mathrm{Sr}^{2+}$ pairs in $\mathrm{SrF}_{2}$ for the ground state electron transfer reaction coordinate is presented in Fig. 3. The description we have just given for the $\mathrm{CaF}_{2}: \mathrm{Yb} / \mathrm{Ca}$ case is now valid after minor obvious adaptations. More details on the independent embedded cluster ingredients are given in Ref. 17 and Table I.

In what follows we will refer to vertical transition energies from the ground states of the $\mathrm{Yb}^{2+}-\mathrm{Ca}^{2+}$ and $\mathrm{Yb}^{2+}-\mathrm{Sr}^{2+}$ pairs which can be read directly from Figs. 2 and 3. We will refer also to vertical absorptions which originate in excited states 


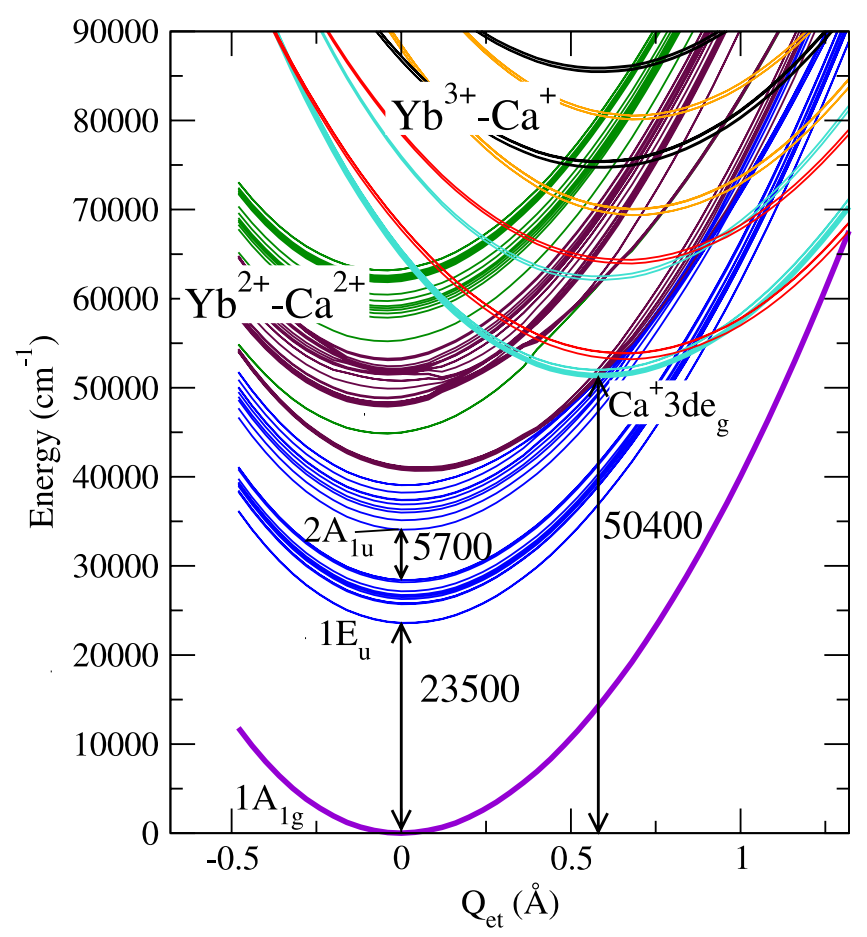

FIG. 2. MMCT configuration coordinate diagram of $\mathrm{Yb} / \mathrm{Ca}$ pairs in $\mathrm{CaF}_{2}$. The normalized electron transfer reaction coordinates $Q_{e t}$ correspond to the ground state of $\mathrm{Yb}^{2+}-\mathrm{Ca}^{2+}$ and to the first excited state of $\mathrm{Yb}^{3+}-\mathrm{Ca}^{+}$pairs (see Fig. 1). Violet, blue, green, and maroon curves correspond to $\mathrm{Yb}^{2+}-\mathrm{Ca}^{2+}$ pair states where the $\left(\mathrm{CaF}_{8}\right)^{6-} 3 s^{2} 3 p^{6}-1 A_{1 \mathrm{~g}}$ ground state is combined with states of the $\left(\mathrm{YbF}_{8}\right)^{6-} 4 f^{14}, 4 f^{13} 5 d e_{g}, 4 f^{13} 5 d t_{2 g}$, and interacting $4 f^{13} 5 d-4 f^{13} a_{1 g}^{Y b T E}$ configurations, respectively. Three of them are indicated by their $\left(\mathrm{YbF}_{8}\right)^{6-}$ part: the $4 f^{14} 1 A_{1 \mathrm{~g}}$ ground state and two metastable $4 f^{13} 5 d e_{g}$ excited states: $1 E_{\mathrm{u}}$ and $2 A_{1 \mathrm{u}}$. The energy gaps below $1 E_{\mathrm{u}}$ and $2 A_{1 \mathrm{u}}$ are also indicated. Cyan, red, orange, and black curves correspond to $\mathrm{Yb}^{3+}-\mathrm{Ca}^{+}$pair states where the $\left(\mathrm{YbF}_{8}\right)^{5-}$ states of the $4 f^{13}\left({ }^{2} F_{7 / 2}\right)$ and $4 f^{13}\left({ }^{2} F_{5 / 2}\right)$ configurations are combined with states of the $\left(\mathrm{CaF}_{8}\right)^{7-} 3 d e_{g}, 4 s, 3 d t_{2 g}$, and $4 p$ configurations, respectively. The vertical offset of the lowest $\mathrm{Yb}^{3+}-\mathrm{Ca}^{+}$host level is indicated.

of the pairs and to MMCT crossings. It should be noted that the relaxed excited state structures of the pairs do not fall in the ground state electron transfer reaction coordinate axis, in general; therefore, specific MMCT configuration coordinate diagrams for the excited states would have to be built. However, the changes between the ground and excited state MMCT configuration coordinate diagrams are hard to distinguish from their figures. Therefore, whereas all transition energies used below for discussions have been calculated using the MMCT diabatic potential energy surfaces of the MMCT states involved, only the diagrams in Figs. 2 and 3 will be used to facilitate visualizing the data and processes.

\section{MECHANISM OF PHOTOCONDUCTIVITY IN $\mathrm{Yb}^{2+}$-DOPED $\mathrm{CaF}_{2}$ AND $\mathrm{SrF}_{2}$}

As mentioned in the Introduction, Moine et al. ${ }^{21}$ showed a close correspondence between the profiles of the absorption and photoconductivity spectra in $\mathrm{Yb}^{2+}$-doped $\mathrm{CaF}_{2}$ and $\mathrm{SrF}_{2}$. The photoconductivity onset coincides with the first $4 f-5 d$ absorption band in $\mathrm{SrF}_{2}$ and with the second in $\mathrm{CaF}_{2}$. This indicated the involvement of $4 f^{13} 5 d$ excited states of the

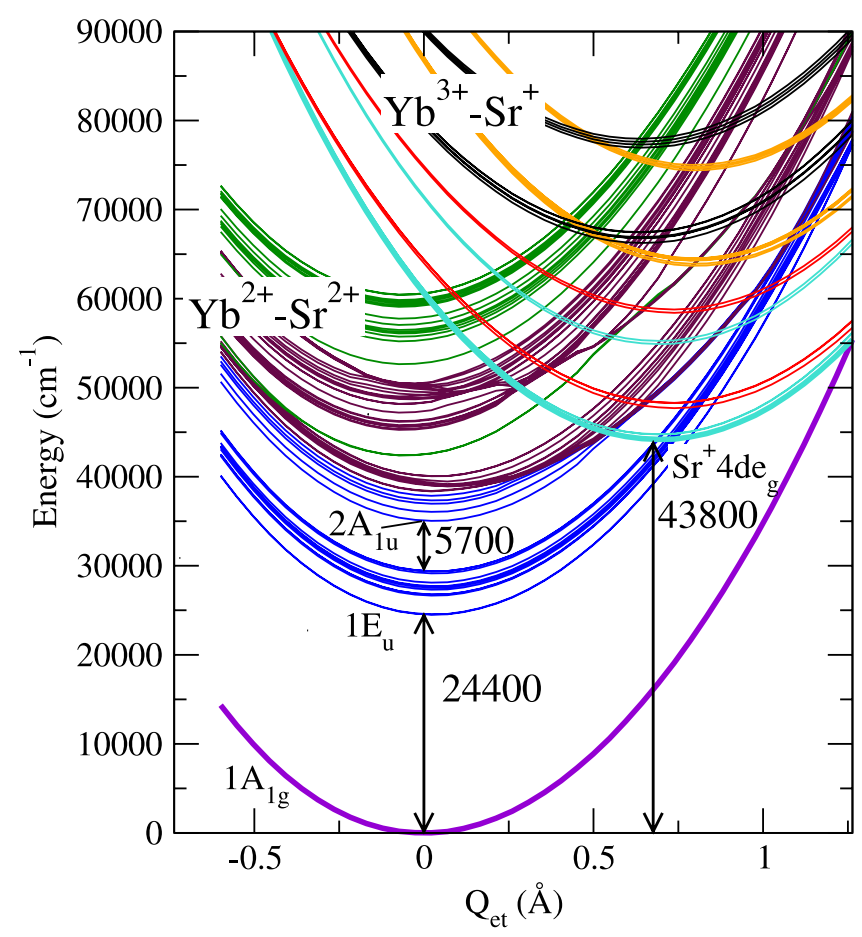

FIG. 3. MMCT configuration coordinate diagram of $\mathrm{Yb} / \mathrm{Sr}$ pairs in $\mathrm{SrF}_{2}$. The normalized electron transfer reaction coordinates correspond to the ground states of $\mathrm{Yb}^{2+}-\mathrm{Sr}^{2+}$ and $\mathrm{Yb}^{3+}-\mathrm{Sr}^{+}$pairs. Violet, blue, green, and maroon curves correspond to $\mathrm{Yb}^{2+}-\mathrm{Sr}^{2+}$ pair states where the $\left(\mathrm{SrF}_{8}\right)^{6-} 4 s^{2} 4 p^{6}-1 A_{1 \mathrm{~g}}$ ground state is combined with states of the $\left(\mathrm{YbF}_{8}\right)^{6-} 4 f^{14}, 4 f^{13} 5 d e_{g}, 4 f^{13} 5 d t_{2 g}$, and interacting $4 f^{13} 5 d-$ $4 f^{13} a_{1 g}^{Y b T E}$ configurations, respectively. Three of them are indicated by their $\left(\mathrm{YbF}_{8}\right)^{6-}$ part: the $4 f^{14} 1 A_{1 \mathrm{~g}}$ ground state and two metastable $4 f^{13} 5 \mathrm{de} g$ excited states: $1 E_{\mathrm{u}}$ and $2 A_{1 \mathrm{u}}$. The energy gaps below $1 E_{\mathrm{u}}$ and $2 A_{1 \mathrm{u}}$ are also indicated. Cyan, red, orange, and black curves correspond to $\mathrm{Yb}^{3+}-\mathrm{Sr}^{+}$pair states where the $\left(\mathrm{YbF}_{8}\right)^{5-}$ states of the $4 f^{13}\left({ }^{2} F_{7 / 2}\right)$ and $4 f^{13}\left({ }^{2} F_{5 / 2}\right)$ configurations are combined with states of the $\left(\mathrm{SrF}_{8}\right)^{7-} 4 d e_{g}, 5 s, 4 d t_{2 g}$, and $5 p$ configurations, respectively. The vertical offset of the lowest $\mathrm{Yb}^{3+}-\mathrm{Sr}^{+}$host level is indicated.

$\mathrm{Yb}^{2+}$ activator in the electron transfer to the host and it was natural to suggest that all the $4 f^{13} 5 d$ states of $\mathrm{Yb}^{2+}$ in $\mathrm{SrF}_{2}$ and all but the lowest in energy in $\mathrm{CaF}_{2}$ lie in the conduction band.

This assumption can be checked by inspection of Figs. 2 and 3, where we show the MMCT configuration coordinate diagrams of $\mathrm{Yb} / \mathrm{Ca}$ pairs in $\mathrm{CaF}_{2}$ and $\mathrm{Yb} / \mathrm{Sr}$ pairs in $\mathrm{SrF}_{2}$, which summarize the results of the $\mathrm{Yb}^{2+}$-to- $\mathrm{Ca}^{2+}$ and $\mathrm{Yb}^{2+}$-to$\mathrm{Sr}^{2+} \mathrm{MMCT}$ calculations performed as described in Section II. In effect, the lowest energy reaction path,

$$
\mathrm{Yb}^{2+} 4 f^{14}+\mathrm{Ca}^{2+} 4 s^{0} \rightarrow \mathrm{Yb}^{3+} 4 f^{13}\left({ }^{2} F_{7 / 2}\right)+\mathrm{Ca}^{+} 3 d e_{g},
$$

in Fig. 2, which connects the two MMCT energy minima of the violet and lowest cyan curves

$$
\left[\mathrm{Yb}^{2+} 1 A_{1 g}, \mathrm{Ca}^{2+} 1 A_{1 g}\right] \rightarrow\left[\mathrm{Yb}^{3+} 1 \Gamma_{7 u}, \mathrm{Ca}^{+} 1 \Gamma_{8 g}\right],
$$

describes the transference of one electron from the lowest (multielectronic) impurity level to the lowest (multielectronic, local) excited host level of the doped crystal to a well-defined and meaningful level of approximation: the diabatic approximation described in Sec. II. The MMCT calculations indicate that the lowest structurally relaxed excited host level lies some $50400 \mathrm{~cm}^{-1}$ above the impurity ground state in the doped 
TABLE II. Vertical transition energies potentially involved in a two-photon dopant-to-host electron transfer mechanism. Results for the dopant-host ion pair $\mathrm{Yb} / \mathrm{Ca}$ in $\mathrm{CaF}_{2}$. Experimental peak energies from $\mathrm{UV}$ absorption spectra of $\mathrm{CaF}_{2}: \mathrm{Yb}^{2+}$ are also included. All energies in $\mathrm{cm}^{-1}$. See text for details and Ref. 44 for additional data.

Photoinduced dopant-to-host electron transfer

First photon absorption from the $\mathrm{Yb}^{2+}-\mathrm{Ca}^{2+}$ ground state

\begin{tabular}{|c|c|c|c|c|c|c|}
\hline $\begin{array}{l}\mathrm{Yb}^{2+} 4 f \rightarrow 5 d \\
\text { absorptions }^{\mathrm{a}}\end{array}$ & Configuration & State & Energy $^{\mathrm{b}}$ & Configuration & State & Energy \\
\hline & & $\mathrm{Yb}^{2+}-\mathrm{Ca}^{2+}$ & & & $\mathrm{Yb}^{2+}-\mathrm{Ca}^{2+}$ & \\
\hline & {$\left[4 f^{14}, 4 s^{0}\right]$} & {$\left[1 A_{1 g}, 1 A_{1 g}\right]^{\mathrm{c}}$} & 0 & & & \\
\hline First band & & & & & & \\
\hline & {$\left[4 f^{13}\left({ }^{2} F_{7 / 2}\right) 5 d e_{g}, 4 s^{0}\right]$} & {$\left[1 E_{u}, 1 A_{1 g}\right]$} & 23600 & {$\left[4 f^{13}\left({ }^{2} F_{7 / 2}\right) 5 d e_{g}, 4 s^{0}\right]$} & {$\left[1 E_{u}, 1 A_{1 g}\right]^{\mathrm{d}}$} & 0 \\
\hline 27400 & & {$\left[1 T_{1 u}, 1 A_{1 g}\right]$} & $25700(1.00)$ & {$\left[4 f^{13}\left({ }^{2} F_{7 / 2}\right) 5 d t_{2 g}, 4 s^{0}\right]$} & {$\left[4 A_{1 u}, 1 A_{1 g}\right]$} & 25800 \\
\hline Second band & & & & & & \\
\hline & {$\left[4 f^{13}\left({ }^{2} F_{5 / 2}\right) 5 d e_{g}, 4 s^{0}\right]$} & {$\left[2 A_{1 u}, 1 A_{1 g}\right]$} & 34100 & {$\left[4 f^{13}\left({ }^{2} F_{5 / 2}\right) 5 d e_{g}, 4 s^{0}\right]$} & $\begin{array}{c}{\left[2 A_{1 u}, 1 A_{1 g}\right]^{\mathrm{e}}} \\
\mathrm{Yb}^{3+}-\mathrm{Ca}^{+}\end{array}$ & 0 \\
\hline 36400 & & {$\left[5 T_{1 u}, 1 A_{1 g}\right]$} & $35100(0.80)$ & {$\left[4 f^{13}\left({ }^{2} F_{7 / 2}\right), 4 s^{1}\right]$} & {$\left[1 \Gamma_{7 u}, 1 \Gamma_{6 g}\right]$} & 32500 \\
\hline & & & & & {$\left[1 \Gamma_{6 u}, 1 \Gamma_{6 g}\right]$} & 33000 \\
\hline & & & & & {$\left[1 \Gamma_{8 u}, 1 \Gamma_{6 g}\right]$} & 33000 \\
\hline 37800 & & {$\left[6 T_{1 u}, 1 A_{1 g}\right]$} & $36900(1.70)$ & {$\left[4 f^{13}\left({ }^{2} F_{5 / 2}\right), 3 d e_{g}^{1}\right]$} & {$\left[2 \Gamma_{7 u}, 1 \Gamma_{8 g}\right]$} & 40400 \\
\hline & & & & & {$\left[2 \Gamma_{8 u}, 1 \Gamma_{8 g}\right]$} & 40800 \\
\hline Third band & & & & & & \\
\hline 43800,44100 & {$\left[4 f^{13}\left({ }^{2} F_{7 / 2}\right) 5 d t_{2 g}, 4 s^{0}\right]^{\mathrm{f}}$} & {$\left[10 T_{1 u}, 1 A_{1 g}\right]$} & $48300(2.10)$ & {$\left[4 f^{13}\left({ }^{2} F_{5 / 2}\right), 4 s^{1}\right]$} & {$\left[2 \Gamma_{7 u}, 1 \Gamma_{6 g}\right]$} & 43200 \\
\hline & & {$\left[11 T_{1 u}, 1 A_{1 g}\right]$} & $48500(0.50)$ & & {$\left[2 \Gamma_{8 u}, 1 \Gamma_{6 g}\right]$} & 43500 \\
\hline 46800 & & {$\left[14 T_{1 u}, 1 A_{1 g}\right]$} & $51600(0.23)$ & {$\left[4 f^{13}\left({ }^{2} F_{7 / 2}\right), 4 p^{1}\right]$} & {$\left[1 \Gamma_{7 u}, 1 \Gamma_{6 u}\right]$} & 51400 \\
\hline & & {$\left[16 T_{1 u}, 1 A_{1 g}\right]$} & $53300(0.56)$ & & {$\left[1 \Gamma_{7 u}, 1 \Gamma_{8 u}\right]$} & 51500 \\
\hline & & & & & {$\left[1 \Gamma_{6 u}, 1 \Gamma_{6 u}\right]$} & 51900 \\
\hline & & & & & {$\left[1 \Gamma_{8 u}, 1 \Gamma_{6 u}\right]$} & 51900 \\
\hline & & & & & {$\left[1 \Gamma_{6 u}, 1 \Gamma_{8 u}\right]$} & 52000 \\
\hline & & & & & {$\left[1 \Gamma_{8 u}, 1 \Gamma_{8 u}\right]$} & 52000 \\
\hline & & & & {$\left[4 f^{13}\left({ }^{2} \boldsymbol{F}_{7 / 2}\right), 3 d t_{2 g}^{1}\right]$} & {$\left[1 \Gamma_{7 u}, 2 \Gamma_{8 g}\right]$} & 52700 \\
\hline & & & & & {$\left[1 \Gamma_{7 u}, 1 \Gamma_{7 g}\right]$} & 52700 \\
\hline & & & & & {$\left[1 \Gamma_{6 u}, 2 \Gamma_{8 g}\right]$} & 53200 \\
\hline & & & & & {$\left[1 \Gamma_{6 u}, 1 \Gamma_{7 g}\right]$} & 53200 \\
\hline & & & & & {$\left[1 \Gamma_{8 u}, 2 \Gamma_{8 g}\right]$} & 53300 \\
\hline & & & & & {$\left[1 \Gamma_{8 u}, 1 \Gamma_{7 g}\right]$} & 53300 \\
\hline
\end{tabular}

a From absorption spectra from Refs. 47 and 48 at $20^{\circ} \mathrm{C}$, and Refs. 45 and 49 at $77 \mathrm{~K}$.

${ }^{\mathrm{b}}$ Only $\mathrm{Yb}^{2+}$ electric dipole allowed $1 A_{1 \mathrm{~g}} \rightarrow \mathrm{n} T_{1 \mathrm{u}}$ absorptions with significant oscillator strengths are given. Absorption oscillator strengths in parentheses; they have been calculated on independent $\left(\mathrm{YbF}_{8}\right)^{6-}$ embedded cluster calculations (see Ref. 17). Two metastable levels are also included.

${ }^{\mathrm{c}} d_{\mathrm{Yb}-\mathrm{F}, e}=2.329 \AA ; d_{\mathrm{Ca}-\mathrm{F}, e}=2.309 \AA$.

${ }^{\mathrm{d}}$ Metastable state reached by $1 T_{1 \mathrm{u}} \rightsquigarrow 1 E_{\mathrm{u}}$ non-radiative decay. $d_{\mathrm{Yb}-\mathrm{F}, e}=2.317 \AA ; d_{\mathrm{Ca}-\mathrm{F}, e}=2.309 \AA$.

${ }^{\mathrm{e}}$ Metastable state reached by $\mathrm{i} T_{1 \mathrm{u}} \rightsquigarrow 2 A_{1 \mathrm{u}}$ non-radiative decay. Energy gap below this state is $5700 \mathrm{~cm}^{-1} \cdot d_{\mathrm{Yb}-\mathrm{F}, e}=2.317 \AA \AA_{\mathrm{Ca}-\mathrm{F}, e}=2.309 \AA$.

${ }^{\mathrm{f}}$ Some states show $4 f^{13}\left({ }^{2} F_{7 / 2}\right) 5 d t_{2 g}-4 f^{13}\left({ }^{2} F_{5 / 2}\right) a_{1 g}^{\mathrm{YbTE}}$ configurational mixing. See text for details.

crystal, as indicated in Fig. 2. The impurity-to-host electron transfer without structural relaxation requires some additional $15000 \mathrm{~cm}^{-1}$. Having in mind that the local host states calculated here are expected to be a lower energy bound of the host delocalized conduction band, the present calculations indicate that the lowest $\mathrm{Yb}^{2+}$ states that lie at or above the lowest excited energy level of the host are the highest states of the $4 f^{13}\left({ }^{2} F_{7 / 2}\right) 5 d t_{2 g}$ manifold (which mix strongly with impuritytrapped excitons, $4 f^{13}\left({ }^{2} F_{5 / 2}\right) a_{1 g}^{Y b T E}$, which extend towards the nearby interstices; see maroon energy curves in Fig. 2). This result does not support the interpretation suggested in Ref. 21. With small differences, the same can be said about the $\mathrm{SrF}_{2}$ host (see Fig. 3).

In this section, based on the results of the MMCT calculations, we propose a two-photon mechanism that explains and is consistent with the experimental features of photoconductivity in these materials. The discussion is based on the illustrative MMCT configuration coordinate diagrams (Figs. 2 and 3) and on the data summarized in Tables II and III. In the tables we show: (1) experimental $\mathrm{Yb}^{2+} 4 f \rightarrow 5 d$ absorptions in $\mathrm{CaF}_{2}$ and $\mathrm{SrF}_{2}$, which coincide with peaks in the experimental photoconductivity spectra (first column); (2) calculated $\mathrm{Yb}^{2+} 4 f \rightarrow 5 d$ vertical transitions from the ground states of the $\mathrm{Yb}^{2+}-\mathrm{Ca}^{2+}$ and $\mathrm{Yb}^{2+}-\mathrm{Sr}^{2+}$ pairs (second set of columns), which can be directly compared with (1); and (3) calculated vertical transitions from selected excited states of the $\mathrm{Yb}^{2+}-\mathrm{Ca}^{2+}$ and $\mathrm{Yb}^{2+}-\mathrm{Sr}^{2+}$ pairs (third set of columns), which, according to the discussions in Sections III A and III B, have a high probability of being metastable and absorbing a second photon, which ultimately produces the impurity-to-host electron transfer. Figs. 4 and 5 
TABLE III. Vertical transition energies potentially involved in a two-photon dopant-to-host electron transfer mechanism. Results for the dopant-host ion pair $\mathrm{Yb} / \mathrm{Sr}$ in $\mathrm{SrF}_{2}$. Experimental peak energies from UV absorption spectra of $\mathrm{SrF}_{2}: \mathrm{Yb}^{2+}$ are also included. All energies in $\mathrm{cm}^{-1}$. See text for details and Ref. 44 for additional data.

Photoinduced dopant-to-host electron transfer

First photon absorption from the $\mathrm{Yb}^{2+}-\mathrm{Sr}^{2+}$ ground state

Second photon absorption from a $\mathrm{Yb}^{2+}-\mathrm{Sr}^{2+}$ metastable state

\begin{tabular}{|c|c|c|c|c|c|c|}
\hline \\
\hline $\begin{array}{l}\mathrm{Yb}^{2+} 4 f \rightarrow 5 d \\
\text { absorptions }^{\mathrm{a}}\end{array}$ & Configuration & State & Energy $^{\mathrm{b}}$ & Configuration & State & Energy \\
\hline & & $\mathrm{Yb}^{2+}-\mathrm{Sr}^{2+}$ & & & $\mathrm{Yb}^{2+}-\mathrm{Sr}^{2+}$ & \\
\hline & {$\left[4 f^{14}, 4 s^{0}\right]$} & {$\left[1 A_{1 g}, 1 A_{1 g}\right]^{\mathrm{c}}$} & 0 & & & \\
\hline \multicolumn{7}{|l|}{ First band } \\
\hline & {$\left[4 f^{13}\left({ }^{2} F_{7 / 2}\right) 5 d e_{g}, 5 s^{0}\right]$} & {$\left[1 E_{u}, 1 A_{1 g}\right]$} & 24500 & {$\left[4 f^{13}\left({ }^{2} F_{7 / 2}\right) 5 d e_{g}, 5 s^{0}\right]$} & {$\left[1 E_{u}, 1 A_{1 g}\right]^{\mathrm{d}}$} & \\
\hline 27950 & & {$\left[1 T_{1 u}, 1 A_{1 g}\right]$} & $26700(1.00)$ & {$\left[4 f^{13}\left({ }^{2} F_{7 / 2}\right) 5 d t_{2 g}, 5 s^{0}\right]^{\mathrm{e}}$} & {$\left[16 T_{1 u}, 1 A_{1 g}\right]$} & 26700 \\
\hline \multicolumn{7}{|l|}{ Second band } \\
\hline & {$\left[4 f^{13}\left({ }^{2} F_{5 / 2}\right) 5 d e_{g}, 5 s^{0}\right]$} & {$\left[2 A_{1 u}, 1 A_{1 g}\right]$} & 35100 & {$\left[4 f^{13}\left({ }^{2} F_{5 / 2}\right) 5 d e_{g}, 5 s^{0}\right]$} & $\begin{array}{c}{\left[2 A_{1 u}, 1 A_{1 g}\right]^{\mathrm{f}}} \\
\mathrm{Yb}^{3+}-\mathrm{Sr}^{+}\end{array}$ & 0 \\
\hline & & {$\left[5 T_{1 u}, 1 A_{1 g}\right]$} & $36100(0.73)$ & {$\left[4 f^{13}\left({ }^{2} F_{5 / 2}\right), 4 d e_{g}^{1}\right]$} & {$\left[2 \Gamma_{7 u}, 1 \Gamma_{8 g}\right]$} & 34500 \\
\hline & & {$\left[6 T_{1 u}, 1 A_{1 g}\right]$} & $37900(1.46)$ & & {$\left[2 \Gamma_{8 u}, 1 \Gamma_{8 g}\right]$} & 34700 \\
\hline & & & & {$\left[4 f^{13}\left({ }^{2} F_{5 / 2}\right), 5 s^{1}\right]$} & {$\left[2 \Gamma_{7 u}, 1 \Gamma_{6 g}\right]$} & 37800 \\
\hline & & & & & {$\left[2 \Gamma_{8 u}, 1 \Gamma_{6 g}\right]$} & 38100 \\
\hline \multicolumn{7}{|l|}{ Third band } \\
\hline \multirow[t]{12}{*}{42700} & {$\left[4 f^{13}\left({ }^{2} F_{7 / 2}\right) 5 d t_{2 g}, 5 s^{0}\right]^{\mathrm{e}}$} & {$\left[10 T_{1 u}, 1 A_{1 g}\right]$} & $45700(1.86)$ & {$\left[4 f^{13}\left({ }^{2} F_{7 / 2}\right), 5 p^{1}\right]$} & {$\left[1 \Gamma_{7 u}, 1 \Gamma_{6 u}\right]$} & 42400 \\
\hline & & {$\left[11 T_{1 u}, 1 A_{1 g}\right]$} & $45900(1.28)$ & & {$\left[1 \Gamma_{6 u}, 1 \Gamma_{6 u}\right]$} & 42800 \\
\hline & & & & & {$\left[1 \Gamma_{8 u}, 1 \Gamma_{6 u}\right]$} & 42800 \\
\hline & & & & & {$\left[1 \Gamma_{7 u}, 1 \Gamma_{8 u}\right]$} & 42800 \\
\hline & & & & & {$\left[1 \Gamma_{6 u}, 1 \Gamma_{8 u}\right]$} & 43200 \\
\hline & & & & & {$\left[1 \Gamma_{8 u}, 1 \Gamma_{8 u}\right]$} & 43300 \\
\hline & & {$\left[14 T_{1 u}, 1 A_{1 g}\right]$} & $48900(0.27)$ & {$\left[4 f^{13}\left({ }^{2} F_{7 / 2}\right), 4 d t_{2 g}^{1}\right]$} & {$\left[1 \Gamma_{7 u}, 2 \Gamma_{8 g}\right]$} & 49700 \\
\hline & & {$\left[15 T_{1 u}, 1 A_{1 g}\right]$} & $50200(0.20)$ & & {$\left[1 \Gamma_{7 u}, 1 \Gamma_{7 g}\right]$} & 50000 \\
\hline & & {$\left[16 T_{1 u}, 1 A_{1 g}\right]$} & $50500(0.51)$ & & {$\left[1 \Gamma_{6 u}, 2 \Gamma_{8 g}\right]$} & 50100 \\
\hline & & & & & {$\left[1 \Gamma_{8 u}, 2 \Gamma_{8 g}\right]$} & 50200 \\
\hline & & & & & {$\left[1 \Gamma_{6 u}, 1 \Gamma_{7 g}\right]$} & 50400 \\
\hline & & & & & {$\left[1 \Gamma_{8 u}, 1 \Gamma_{7 g}\right]$} & 50400 \\
\hline
\end{tabular}

a From absorption spectra from Refs. 47 and 48 at $20^{\circ} \mathrm{C}$, and Refs. 45 and 49 at $77 \mathrm{~K}$.

${ }^{\mathrm{b}}$ Only $\mathrm{Yb}^{2+}$ electric dipole allowed $1 A_{1 \mathrm{~g}} \rightarrow \mathrm{n} T_{1 \mathrm{u}}$ absorptions with significant oscillator strengths are given. Absorption oscillator strengths in parentheses; they have been calculated on independent $\left(\mathrm{YbF}_{8}\right)^{6-}$ embedded cluster calculations (see Ref. 17). Two metastable levels are also included.

${ }^{\mathrm{c}} d_{\mathrm{Yb}-\mathrm{F}, e}=2.413 \AA ; d_{\mathrm{Sr}-\mathrm{F}, e}=2.464 \AA$.

${ }^{\mathrm{d}}$ Metastable state reached by $1 T_{1 \mathrm{u}} \rightsquigarrow 1 E_{\mathrm{u}}$ non-radiative decay. $d_{\mathrm{Yb}-\mathrm{F}, e}=2.396 \AA$ 派 $d_{\mathrm{Ca}-\mathrm{F}, e}=2.464 \AA$.

${ }^{\mathrm{e}}$ Some states show $4 f^{13}\left({ }^{2} F_{7 / 2}\right) 5 d t_{2 g}-4 f^{13}\left({ }^{2} F_{5 / 2}\right) a_{1 g}^{\mathrm{YbTE}}$ configurational mixing. See text for details.

${ }^{\mathrm{f}}$ Metastable state reached by i $T_{1 \mathrm{u}} \rightsquigarrow 2 A_{1 \mathrm{u}}$ non-radiative decay. Energy gap below this state is $5700 \mathrm{~cm}^{-1} \cdot d_{\mathrm{Yb}-\mathrm{F}, e}=2.395 \AA$; $d_{\mathrm{Ca}-\mathrm{F}, e}=2.464 \AA$.

are also used in Sections III A and III B . They contain replicas of Figs. 2 and 3, respectively, where all $\mathrm{Yb}^{3+}-\mathrm{Ca}^{+}\left(\mathrm{Sr}^{+}\right)$energy curves are kept while only the $\mathrm{Yb}^{2+}-\mathrm{Ca}^{2+}\left(\mathrm{Sr}^{2+}\right)$ energy curves relevant to the discussions are plotted to favour visualizing the mechanisms.

\section{A. Dopant-to-host electron transfer in $\mathrm{CaF}_{2}: \mathrm{Yb}^{2+}$}

The calculated vertical transition energies from the $\mathrm{Yb}^{2+}$ $-\mathrm{Ca}^{2+}\left[1 A_{1 \mathrm{~g}}, 1 A_{1 \mathrm{~g}}\right]$ ground state minimum presented in Table II (fourth column), $\left[1 A_{1 \mathrm{~g}}, 1 A_{1 \mathrm{~g}}\right] \rightarrow\left[\mathrm{i} T_{1 \mathrm{u}}, 1 A_{1 \mathrm{~g}}\right]$, correspond to the electric dipole allowed $4 f^{14} \rightarrow 4 f^{13} 5 d$ transitions of the $\mathrm{Yb}^{2+}$ active center. Only those having significant absorption oscillator strengths in the independent embedded cluster calculations are tabulated (see Ref. 17 for details). The ground state absorption spectrum consists of several multi-origin bands separated by energy gaps. Consequently, the experimental and theoretical transition energies in columns 1 and 4 are grouped using the labels first/second/third band and horizontal lines in Table II. The lowest electric dipole allowed absorption in the first, second, and third bands $\left(\left[1 A_{1 \mathrm{~g}}, 1 A_{1 \mathrm{~g}}\right] \rightarrow\left[1 T_{1 \mathrm{u}}, 1 A_{1 \mathrm{~g}}\right]\right.$, $\left[5 T_{1 \mathrm{u}}, 1 A_{1 \mathrm{~g}}\right]$, and $\left.\left[10 T_{1 \mathrm{u}}, 1 A_{1 \mathrm{~g}}\right]\right)$ are also indicated as black arrows in the (a), (b), and (c) MMCT diagrams of Fig. 4, respectively (note the simplified nomenclature used in the figures, where only the state of the $\left(\mathrm{YbF}_{8}\right)^{6-}$ moiety is indicated). Two large energy gaps are found in the absorption spectrum ${ }^{44}$ which could render the states lying above them somewhat stable against non-radiative relaxation: the first one $\left(23500 \mathrm{~cm}^{-1}\right)$ is below the first excited state $\left[1 E_{\mathrm{u}}, 1 A_{1 \mathrm{~g}}\right]$ with $\mathrm{Yb}^{2+}$ in the $4 f^{13}\left({ }^{2} F_{7 / 2}\right) 5 d e_{g}$ configuration; the second one $\left(5700 \mathrm{~cm}^{-1}\right)$ is below the $\left[2 A_{1 \mathrm{u}}, 1 A_{1 \mathrm{~g}}\right]$ state with $\mathrm{Yb}^{2+}$ in the $4 f^{13}\left({ }^{2} F_{5 / 2}\right) 5 d e_{g}$ configuration (see both energy gaps in the full diagram of Fig. 2). The $2 A_{1 \mathrm{u}}$ excited state of $\mathrm{Yb}^{2+}$ has been found to be responsible for the IVCT emission of $\mathrm{Yb}^{2+}-\mathrm{Yb}^{3+}$ pairs in $\mathrm{CaF}_{2}$, commonly know as the anomalous emission. ${ }^{17} \mathrm{In}$ the last column of Table II we have included some verti- 
(a)

(b)

(c)

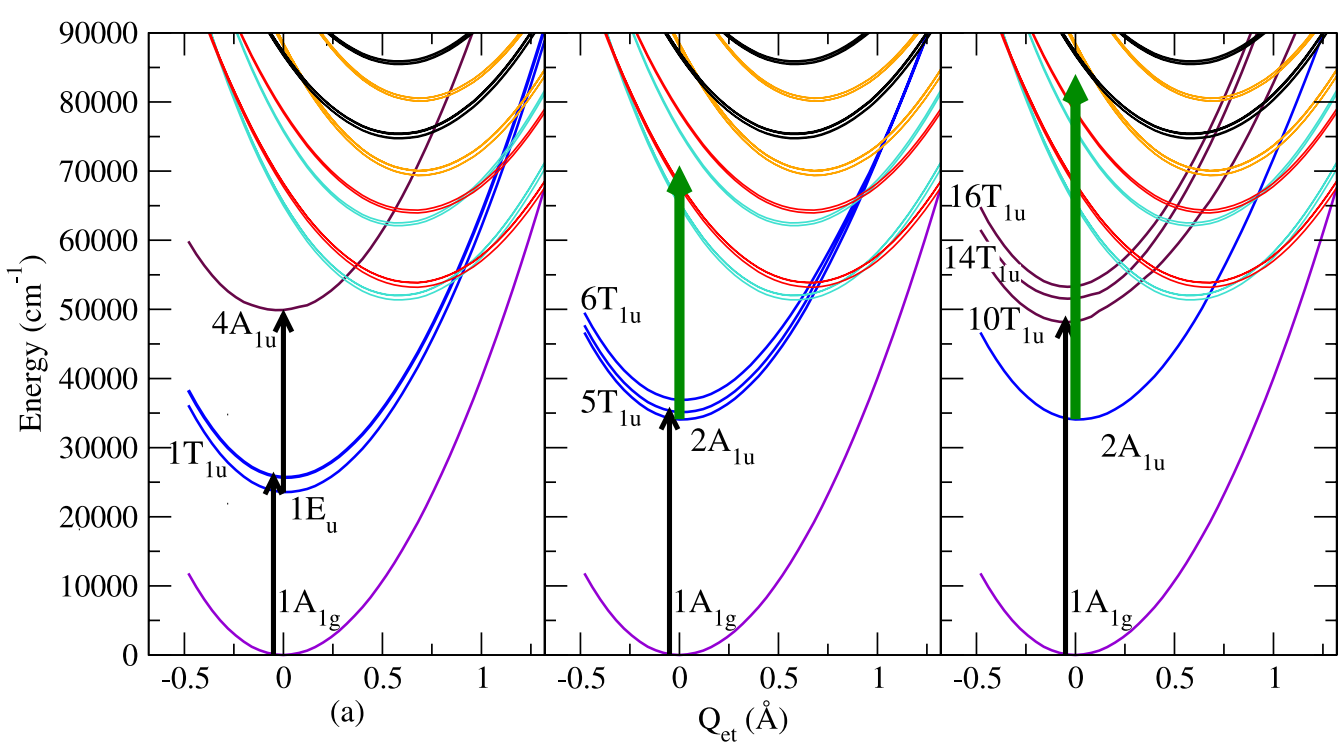

FIG. 4. $\mathrm{Yb}^{2+}$-doped $\mathrm{CaF}_{2}$ : Two-photon mechanism potentially leading to photoconductivity at the wavelengths of the first (a), second (b), and third (c) $\mathrm{Yb}^{2+}$ absorption bands. Black arrows: intra- $\mathrm{Yb}^{2+}$ transitions; green arrows dopant-to-host MMCT transitions. (a) The two-photon process does not lead to photoconductivity but to intra- $\mathrm{Yb}^{2+}$ transitions. (b) and (c) the two-photon process leads to dopant-to-host MMCT, hence to photoconductivity. In all cases all calculated $\mathrm{Yb}^{3+}-\mathrm{Ca}^{+}$states are plotted but only the $\mathrm{Yb}^{2+}-\mathrm{Ca}^{2+}$ states potentially involved in the photoconductivity mechanism are plotted and are labeled referring to the $\left(\mathrm{YbF}_{8}\right)^{6-}$ state which is combined with the $\left(\mathrm{CaF}_{8}\right)^{6-}$ ground state. See Fig. 2 and its caption for the full diagram and meaning of colors associated with the energy curves. See text for details.

cal transitions from the minima of the two metastable states $\mathrm{Yb}^{2+}-\mathrm{Ca}^{2+}\left[1 E_{\mathrm{u}}, 1 A_{1 \mathrm{~g}}\right]$ and $\left[2 A_{1 \mathrm{u}}, 1 A_{1 \mathrm{~g}}\right]$, which will be used in the following discussion.

Given the correlation observed between the absorption and photoconductivity spectra, ${ }^{21}$ it is interesting to examine the
MMCT configuration coordinate diagram in Figs. 2 and 4 in order to check if the photons that are absorbed in the $\mathrm{Yb}^{2+} 4 f^{14}$ $\rightarrow 4 f^{13} 5 d$ excitations are also able to induce dopant-to-host electron transfer from metastable excited states. Let us start with the first absorption band [Table II and Fig. 4(a)]. The (a)

(b)

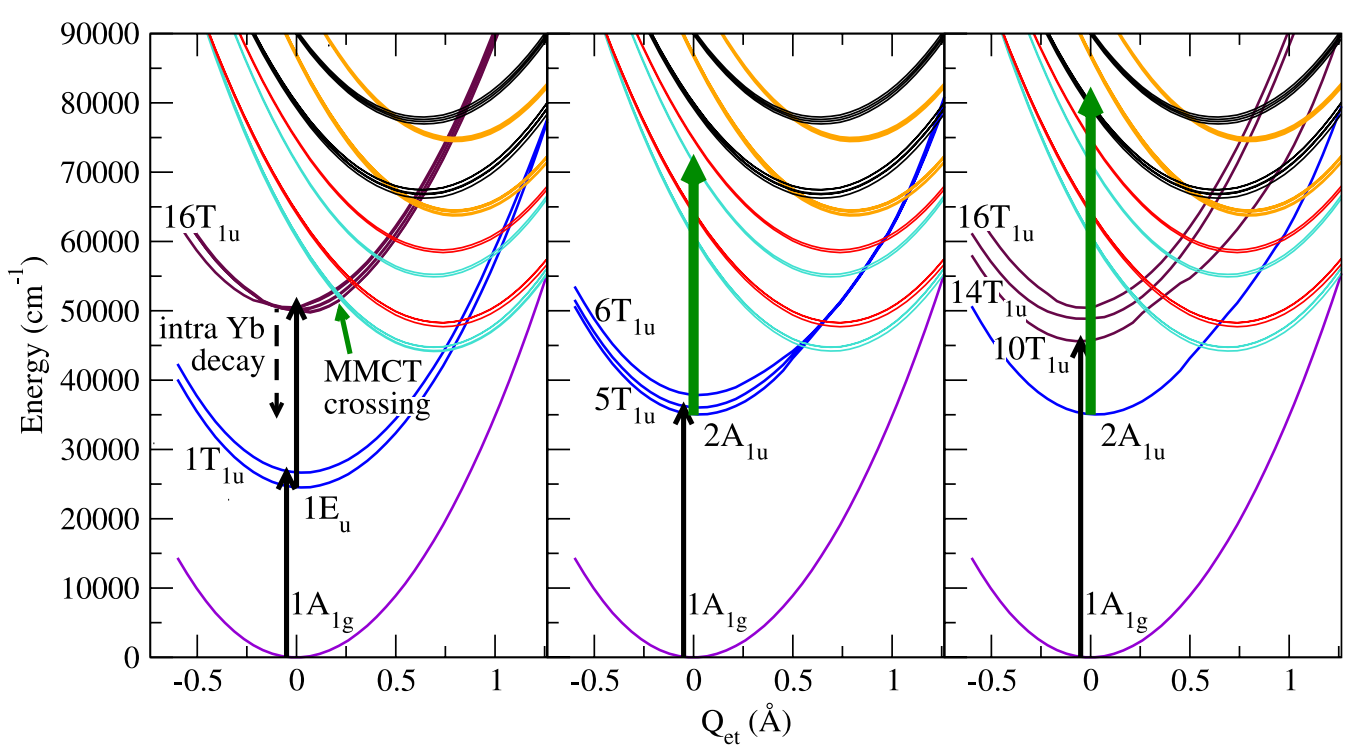

FIG. 5. $\mathrm{Yb}^{2+}$-doped $\mathrm{SrF}_{2}$ : Two-photon mechanism potentially leading to photoconductivity at the wavelengths of the first (a), second (b), and third (c) $\mathrm{Yb}^{2+}$ absorption bands. Black arrows: intra- $\mathrm{Yb}^{2+}$ transitions; green arrows dopant-to-host MMCT transitions. (a) The intra-Yb two-photon process is followed by two competing non-radiative pathways: intra-Yb non-radiative decay and non-radiative MMCT crossing, hence to low intensity photocurrent. In all cases all calculated $\mathrm{Yb}^{3+}-\mathrm{Sr}^{+}$states are plotted but only the $\mathrm{Yb}^{2+}-\mathrm{Sr}^{2+}$ states potentially involved in the photoconductivity mechanism are plotted and are labeled referring to the $\left(\mathrm{YbF}_{8}\right)^{6-}$ state which is combined with the $\left(\mathrm{SrF}_{8}\right)^{6-}$ ground state. See Fig. 3 and its caption for the full diagram and meaning of colors associated with the energy curves. See text for details. 
first intra- $\mathrm{Yb} 4 f_{7 / 2} \rightarrow 5 d e_{g}$ vertical transition $\left[1 A_{1 g}, 1 A_{1 g}\right]$ $\rightarrow\left[1 T_{1 u}, 1 A_{1 g}\right]\left[25700 \mathrm{~cm}^{-1}\right.$; black arrow in Fig. 4(a)], is followed by $1 T_{1 u} \rightsquigarrow 1 E_{\mathrm{u}}$ intra-Yb non-radiative relaxation that leads to the $\left[1 E_{\mathrm{u}}, 1 A_{1 \mathrm{~g}}\right]$ state. From here, a second photon of the same energy could be absorbed, in principle, as illustrated by the second black arrow in Fig. 4(a). However, although this second photon absorption can produce a second intra- $\mathrm{Yb}$ excitation $\left(\left[1 E_{\mathrm{u}}, 1 A_{1 \mathrm{~g}}\right] \rightarrow\left[4 A_{1 u}, 1 A_{1 \mathrm{~g}}\right]\right),{ }^{44}$ it cannot reach any of the $\mathrm{Yb}^{3+}-\mathrm{Ca}^{+}$states; hence dopant-to-host electron transfer cannot follow the first absorption band. In effect, the lowest MMCT vertical transition from the $\left[1 E_{u}, 1 A_{1 g}\right]$ minimum, $\mathrm{Yb}^{2+}-\mathrm{Ca}^{2+}\left[1 E_{u}, 1 A_{1 g}\right] \rightarrow \mathrm{Yb}^{3+}-\mathrm{Ca}^{+}\left[1 \Gamma_{7 u}, 1 \Gamma_{8 g}\right]$, requires $40200 \mathrm{~cm}^{-1}$ according to our MMCT calculations (Ref. 44). This result is consistent with and explains the fact that no photoconductivity is observed at the wavelengths corresponding to the first intra- $\mathrm{Yb}$ absorption band in the $\mathrm{CaF}_{2}: \mathrm{Yb}^{2+}$ material. ${ }^{21}$

Using the same strategy, we can now examine whether photoinduced dopant-to-host electron transfer can follow higher energy absorptions (cf. Table II). To help visualizing the two-photon mechanism applicable at the wavelengths of the first peak of the second $\left(\left[1 A_{1 \mathrm{~g}}, 1 A_{1 \mathrm{~g}}\right] \rightarrow\left[5 T_{1 \mathrm{u}}, 1 A_{1 \mathrm{~g}}\right]\right)$ and third $\left(\left[1 A_{1 \mathrm{~g}}, 1 A_{1 \mathrm{~g}}\right] \rightarrow\left[10 T_{1 \mathrm{u}}, 1 A_{1 \mathrm{~g}}\right]\right)$ bands of the absorption spectrum [black arrows in Figs. 4(b) and 4(c)], a second (green) arrow of the same length as that corresponding to the first photon absorption has been plotted in Figs. 4(b) and $4(\mathrm{c})$. The origin of the second arrow is, in both cases, the $\mathrm{Yb}^{2+}-\mathrm{Ca}^{2+}\left[2 A_{1 \mathrm{u}}, 1 A_{1 \mathrm{~g}}\right]$ excited state, which would be populated after intra-Yb $5 T_{1 u} \rightsquigarrow 2 A_{1 u}$ or $10 T_{1 u} \rightsquigarrow 2 A_{1 \mathrm{u}}$ nonradiative relaxation. Population of the $2 A_{1 \mathrm{u}}$ state is favoured by the $5700 \mathrm{~cm}^{-1}$ energy gap below it, which can be expected to slow down further non-radiative relaxation, this making $2 A_{1 \mathrm{u}}$ excited state absorptions likely. We must note that the second and third bands of the absorption spectrum contain more than one electric dipole allowed transition (see Table II), which could also lead to a second photon absorption from the $\left[2 A_{1 \mathrm{u}}, 1 A_{1 \mathrm{~g}}\right]$ state. For this reason, in Table II we have aligned the $\left[1 A_{1 \mathrm{~g}}, 1 A_{1 \mathrm{~g}}\right]$ ground state absorptions and the $\left[2 A_{1 \mathrm{u}}, 1 A_{1 \mathrm{~g}}\right]$ excited state absorptions so as to facilitate the discussion on the feasibility of a two-photon dopant-to-host electron transfer. It is well-known that the MMCT absorption bands are extremely wide due to the large horizontal offset between the initial and final states (see Figs. 2 and 3). This means that the vertical $\mathrm{Yb}^{2+}-\mathrm{Ca}^{2+} \rightarrow \mathrm{Yb}^{3+}-\mathrm{Ca}^{+}$excited state absorptions collected in Table II correspond to peak energies of MMCT bands which are much wider than the intra-Yb ground state absorptions. This characteristic is favourable to the two-photon one color mechanism we are examining.

The results of the calculations presented in Fig. 4(b) and Table II suggest that dopant-to-host electron transfer starts as the second band $\left(\mathrm{Yb}^{2+} 4 f_{5 / 2} \rightarrow 5 d e_{g}\right)$ of the absorption spectrum begins and can occur following the two main intra-Yb transitions that form it: $\left[1 A_{1 \mathrm{~g}}, 1 A_{1 \mathrm{~g}}\right] \rightarrow\left[5 T_{1 \mathrm{u}}, 1 A_{1 \mathrm{~g}}\right]$ $\left(35100 \mathrm{~cm}^{-1}\right)$ and $\left[1 A_{1 \mathrm{~g}}, 1 A_{1 \mathrm{~g}}\right] \rightarrow\left[6 T_{1 \mathrm{u}}, 1 A_{1 \mathrm{~g}}\right]\left(36900 \mathrm{~cm}^{-1}\right)$, because $\mathrm{Yb}^{3+}-\mathrm{Ca}^{+}$states can be reached after absorption of a second photon of the same energy in both cases. So, after exciting the $\left[5 T_{1 \mathrm{u}}, 1 A_{1 \mathrm{~g}}\right]$ state and populating non-radiatively the $\left[2 A_{1 \mathrm{u}}, 1 A_{1 \mathrm{~g}}\right]$ state, a $\mathrm{Yb}^{2+} 5 d e_{\mathrm{g}} \rightarrow \mathrm{Ca}^{+} 4 s$ electron transfer, accompanied by $4 f_{7 / 2} \rightarrow 4 f_{5 / 2}$ deexcitation of the $4 f^{13}$ subshell of $\mathrm{Yb}^{2+}$ can occur [see Table II and Fig. 4(b)]. Simi- larly, the more intense $\left[1 A_{1 \mathrm{~g}}, 1 A_{1 \mathrm{~g}}\right] \rightarrow\left[6 T_{1 \mathrm{u}}, 1 A_{1 \mathrm{~g}}\right]$ intra- $\mathrm{Yb}$ transition can be followed by a simpler (now monoelectronic) $\mathrm{Yb}^{2+} 5 d e_{g} \rightarrow \mathrm{Ca}^{+} 3 d e_{g}$ MMCT (see Table II; the second set of black and green arrows are not shown in Fig. 4(b) for clarity). The bielectronic and monoelectronic nature of the two types of MMCT absorptions we have just mentioned indicates that the latter should be faster and more intense. Given that the present calculations assume the diabatic approximation, transition moments between MMCT states cannot be calculated. Yet, inspection of the wavefunctions of the initial and final states in the line we have just described, sets a qualitative, but correct, description of the matter. Analogous analyses have been applied to the IVCT luminescence of $\mathrm{Ce}^{3+}$ in elpasolites and of $\mathrm{Yb}^{2+}$ in fluorites to conclude that the former should be a faster transition than the latter in agreement with experimental evidences (see Refs. 16 and 17, and references therein). All of these results of the calculations agree with the photoconductivity spectrum measured for $\mathrm{CaF}_{2}: \mathrm{Yb}^{2+}$ in the second band region: Photoconductivity begins at $35000 \mathrm{~cm}^{-1}$ and the envelope of the photoconductivity spectrum reveals two photocurrent peaks within the second absorption band wavelength range, the second being higher than the first, in close correspondence with the envelope of the second absorption band and with the two-photon MMCT mechanism we have just described.

Moving forward to the third band of the absorption spectrum [Table II and Fig. 4(c)] we find its first peak $\left[1 A_{1 \mathrm{~g}}, 1 A_{1 \mathrm{~g}}\right]$ $\rightarrow\left[10 T_{1 \mathrm{u}}, 1 A_{1 \mathrm{~g}}\right]\left(48300 \mathrm{~cm}^{-1}\right)$ is the most intense in this wavelength region and is significantly more intense than the lower energy peaks discussed so far, in agreement with experiment. ${ }^{45}$ However, the discrepancies of the calculated electronic transitions with the experimental peak energies are larger in this part of the spectrum than those found for the lower energy transitions, as can be seen in Table II. (The same is true for the $\mathrm{SrF}_{2}: \mathrm{Yb}^{2+}$ case discussed below, although the discrepancies are attenuated.) Exploratory calculations have revealed that improvements in the representation of the second neighbor $\mathrm{Ca}^{2+}$ ions in the $\left(\mathrm{YbF}_{8}\right)^{6-}$ independent embedded cluster calculations results in a lowering of the $4 f^{13} 5 d t_{2 g}$ states by about $3500 \mathrm{~cm}^{-1}$ at the same time that the lower part of the spectrum remains basically unchanged: $1 T_{1 \mathrm{u}} 25800$; $5 T_{1 \mathrm{u}} 35300 ; 6 T_{1 \mathrm{u}} 37000 ; 10 T_{1 \mathrm{u}} 44900 ; 16 T_{1 \mathrm{u}} 50200$, in $\mathrm{cm}^{-1}$. Such calculations treat the $\mathrm{Ca}^{2+} 4 s^{2} 4 p^{6}$ explicitly as valence shells and use a significantly larger $s p d$ basis set at the $\mathrm{Ca}$ second neighbor sites. Since the energy of the $4 f^{13} 5 d e_{g}$ states is virtually not affected by changing the second neighbor representation, the MMCT transitions originating in the $\left[2 A_{1 \mathrm{u}}, 1 A_{1 \mathrm{~g}}\right]$ state, presented in Table II, should not be altered either, and the accuracy of these MMCT transitions and the MMCT transitions discussed above should be similar. Furthermore, given that the photoconductivity spectrum presented in Figs. 7 and 8 of Ref. 21 shows the photocurrent up to $43500 \mathrm{~cm}^{-1}$ only (approximately) and that the improvements make the calculations more demanding, we have not included them in the calculations presented in this paper, whose representation of the second neighbor $\mathrm{Ca}^{2+}$ ions has been described in Section II and Ref. 17 and corresponds to using the $\mathrm{Ca}^{2+}$ embedding AIMP plus a minimal $s p$ basis set, which enforces strong orthogonality between the cluster wavefunctions and the 
crystalline environment, especially with the $\mathrm{Ca}^{2+}$ ions. Taking all of this into account, the end of the experimentally measured photoconductivity spectrum is reached and explained by the two-photon MMCT absorption involving, first, the intense $\left[1 A_{1 \mathrm{~g}}, 1 A_{1 \mathrm{~g}}\right] \rightarrow\left[10 T_{1 \mathrm{u}}, 1 A_{\mathrm{gg}}\right]$ transition $44900 \mathrm{~cm}^{-1}$ [black arrow in Fig. 4(c)], then, $10 T_{1 \mathrm{u}} \rightsquigarrow 2 A_{1 \mathrm{u}}$ non-radiative relaxation, and, finally, monoelectronic (hence, fast and intense) $\mathrm{Yb}^{2+} 5 d e_{g} \rightarrow \mathrm{Ca}^{+} 4 s^{1}$ electron transfer, $\left[2 A_{1 \mathrm{u}}, 1 A_{1 \mathrm{~g}}\right] \rightarrow\left[2 \Gamma_{7 u / 8 u}\right.$, $1 \Gamma_{6 g}$ ] [see Table II and green arrow in Fig. 4(c)]. Again, the results of the calculations are consistent with the shape of the experimental photoconductivity spectrum: After the two photocurrent peaks observed in the second absorption band energy region between 36000 and $38000 \mathrm{~cm}^{-1}$, a very intense rise of the photocurrent is shown at around $40000 \mathrm{~cm}^{-1}$, coinciding with the beginning of the third band of the absorption spectrum (see Fig. 8 of Ref. 21).

\section{B. Dopant-to-host electron transfer in $\mathrm{SrF}_{2}: \mathrm{Yb}^{2+}$}

The results of the $\mathrm{Yb} / \mathrm{Sr}$ MMCT calculations in the $\mathrm{SrF}_{2}: \mathrm{Yb}^{2+}$ material have been organized and are presented in the same way as those of $\mathrm{CaF}_{2}: \mathrm{Yb}^{2+}$ described above. They can be found in Table III and Figs. 3 and 5. The discrepancies between the intra- $\mathrm{Yb}$ vertical absorptions and the experimental peak energies available are smaller now (see Table III). Exploratory calculations on the $\left(\mathrm{YbF}_{6} \mathrm{Sr}_{12}\right)^{20-}$ cluster embedded in $\mathrm{SrF}_{2}$, in which the representation of the $\mathrm{Sr}^{2+}$ second neighbors is improved, indicate that the overestimations of the energies of the $4 f^{13} 5 d t_{2 g}$ states is lower than in the $\mathrm{CaF}_{2}$ case: $1500-2000 \mathrm{~cm}^{-1}$; again, the effects on the $4 f^{13} 5 d e_{g}$ states is very small $\left(\leq 200 \mathrm{~cm}^{-1}\right)$.

The effects of changing the host from $\mathrm{CaF}_{2}$ to $\mathrm{SrF}_{2}$ are smaller in the intra- $\mathrm{Yb}$ absorption spectrum, $\left[1 A_{1 \mathrm{~g}}, 1 A_{1 \mathrm{~g}}\right]$ $\rightarrow\left[\mathrm{i} T_{\mathrm{lu}}, 1 A_{1 \mathrm{~g}}\right]$, than in the adiabatic dopant-to-host electron transfer energy (i.e., the energy difference between the $D_{0}^{+} A_{0}^{-}$ and $D_{0} A_{0}$ ground states at their equilibrium structures). The smaller crystal field in the $\mathrm{SrF}_{2}$ host slightly shifts the $\mathrm{Yb}^{2+}$ $4 f^{14} \rightarrow 4 f^{13} 5 d e_{g}$ and $4 f^{14} \rightarrow 4 f^{13} 5 d t_{2 g}$ transitions to higher and lower energies, respectively, relative to their $\mathrm{CaF}_{2}$ values (see Tables II and III, and Figs. 2 and 3). In contrast, the adiabatic dopant-to-host electron transfer energy changes significantly with the host: from $50400 \mathrm{~cm}^{-1}$ in $\mathrm{CaF}_{2}: \mathrm{Yb}^{2+}$ to $43800 \mathrm{~cm}^{-1}$ in $\mathrm{SrF}_{2}: \mathrm{Yb}^{2+}$, as can be seen in Figs. 2 and 3 (these values are calculated using $d_{\mathrm{Yb}-\mathrm{Ca}}=3.8629 \AA$ and $d_{\mathrm{Yb}-\mathrm{Sr}}=4.0984 \AA$, respectively, in Eq. (2)). This larger effect determines the host specific features of photoconductivity, as shown next.

Let us discuss the photoconductivity mechanism for the second and third absorption bands in a first place and complete the discussion of the first band later on.

The results presented in Table III and Figs. 5(b) and 5(c) for $\mathrm{SrF}_{2}: \mathrm{Yb}^{2+}$ suggest that the mechanism applicable to photoconductivity at wavelengths corresponding to the second and third absorption bands is basically the same as that described and discussed above for $\mathrm{CaF}_{2}: \mathrm{Yb}^{2+}$, which means that the electron transfer is directly induced by the second photon absorption (green arrows). The main difference in this higher energy regions of the photoconductivity spectra of $\mathrm{CaF}_{2}$ and $\mathrm{SrF}_{2}$ can be associated with the fact that the $\mathrm{Yb}^{3+}-\mathrm{Sr}^{+}$levels are now relatively lower, so that the host levels reached by the second photon absorption are higher than in the $\mathrm{CaF}_{2}$ host (compare the reach of the green arrows in panels (b) and (c) of Figs. 4 and 5), and this circumstance affects the relative intensity of the photocurrent peaks. So, coinciding with the second absorption band, the dopant-to-host electron transfers following the first photon absorptions to the $\left[5 T_{1 \mathrm{u}}, 1 A_{1 \mathrm{~g}}\right]$ $\left(36100 \mathrm{~cm}^{-1}\right)$ and $\left[6 T_{1 \mathrm{u}}, 1 A_{1 \mathrm{~g}}\right]\left(37900 \mathrm{~cm}^{-1}\right)$ states and their non-radiative relaxations to the $\left[2 A_{1 \mathrm{u}}, 1 A_{1 \mathrm{~g}}\right]$ state, are now of the monoelectronic type: $\mathrm{Yb}^{2+} 5 d e_{g} \rightarrow \mathrm{Sr}^{+} 4 d e_{g}^{1}$ and $5 s^{1}$, respectively [see Table III and Fig. 5(b), where only the twophoton mechanism beginning with the lowest $1 A_{1 \mathrm{~g}} \rightarrow 5 T_{1 \mathrm{u}}$ transition is indicated with arrows for clarity]. However, coinciding with the third absorption band, the two second-photon induced electron transfers that occur after the first two very intense absorptions $\left[1 A_{1 \mathrm{~g}}, 1 A_{1 \mathrm{~g}}\right] \rightarrow\left[10 T_{1 \mathrm{u}}, 1 A_{1 \mathrm{~g}}\right]\left(\right.$ about $43700 \mathrm{~cm}^{-1}$ ) and $\left[11 T_{1 \mathrm{u}}, 1 A_{1 \mathrm{~g}}\right]$ (about $44000 \mathrm{~cm}^{-1}$ ), and their non-radiative relaxations to the $\left[2 A_{1 \mathrm{u}}, 1 A_{1 \mathrm{~g}}\right]$ state, are of the bielectronic type: the $\mathrm{Yb}^{2+} 5 d e_{g} \rightarrow \mathrm{Sr}^{+} 5 p$ electron transfer is accompanied by $4 f_{7 / 2} \rightarrow 4 f_{5 / 2}$ deexcitation of the $4 f^{13}$ subshell (see Table III and Fig. 5(c)). All of this is consistent with the following change in relative intensity of the photoconductivity spectra of $\mathrm{CaF}_{2}$ and $\mathrm{SrF}_{2}$ in these regions: The second band photocurrent as compared with the third band photocurrent, is much stronger in $\mathrm{SrF}_{2}$ than in $\mathrm{CaF}_{2}$, as can be seen comparing Figs. 7 and 8 of Ref. 21).

Let us now discuss the first photoconductivity band, which is specific of $\mathrm{SrF}_{2}: \mathrm{Yb}^{2+}$ and does not exist in $\mathrm{CaF}_{2}: \mathrm{Yb}^{2+} \cdot{ }^{21} \mathrm{The}^{3}$ shift to lower energies of the $\mathrm{Yb}^{3+}-\mathrm{Sr}^{+}$host levels, relative to the $\mathrm{Yb}^{2+}-\mathrm{Sr}^{2+}$ ground state, with respect to what happens in $\mathrm{CaF}_{2}: \mathrm{Yb}^{2+}$, enables dopant-to-host electron transfer at the wavelengths of the first absorption band of $\mathrm{Yb}^{2+}$-doped $\mathrm{SrF}_{2}$, in agreement with the experimental finding that the onset of the absorption and photoconductivity spectra coincide in the $\mathrm{SrF}_{2}: \mathrm{Yb}^{2+}$ material. ${ }^{21}$ However, the mechanism of this low energy dopant-to-host electron transfer is different from that of the higher energy photoconductivity bands of $\mathrm{CaF}_{2}: \mathrm{Yb}^{2+}$ and $\mathrm{SrF}_{2}: \mathrm{Yb}^{2+}$, according to our calculations, although it still is a two-photon mechanism. It is illustrated in Fig. 5(a): A first photon produces the intra-Yb $\left[1 A_{1 \mathrm{~g}}, 1 A_{1 \mathrm{~g}}\right] \rightarrow\left[1 T_{1 \mathrm{u}}, 1 A_{1 \mathrm{~g}}\right]$ transition $\left(26700 \mathrm{~cm}^{-1}\right)$ responsible for the first band in the absorption spectrum (lowest black arrow). A second photon of the same energy (higher black arrow) can be absorbed from the lower $\left[1 E_{\mathrm{u}}, 1 A_{1 \mathrm{~g}}\right]$ state after $1 T_{1 \mathrm{u}} \leadsto 1 E_{\mathrm{u}}$ non-radiative relaxation. Taking into account that the present calculations overestimate the energy of the $\mathrm{Yb}^{2+} 4 f^{13} 5 d t_{2 g}$ states by some $2000 \mathrm{~cm}^{-1}$, the second photon should reach the top of the $\left[4 f^{13}\left({ }^{2} F_{7 / 2}\right) 5 d t_{2 g}, 4 s^{0}\right]$ manifold, $\left[1 E_{\mathrm{u}}, 1 A_{1 \mathrm{~g}}\right] \rightarrow\left[16 T_{1 \mathrm{u}}, 1 A_{1 \mathrm{~g}}\right]$ $\left(26700 \mathrm{~cm}^{-1}\right.$ from the $\left[1 E_{\mathrm{u}}, 1 A_{1 \mathrm{~g}}\right]$ minimum). From here, nonradiative relaxation can follow two different pathways: intra$\mathrm{Yb}$ non-radiative decay and $\mathrm{Yb}^{2+}$-to- $\mathrm{Sr}^{+} \mathrm{MMCT}$ non-radiative relaxation. The former is indicated with a black downwards slashed arrow; the latter is indicated with a green arrow pointing towards some possible $\mathrm{Yb}^{2+}-\mathrm{Sr}^{2+}$ and $\mathrm{Yb}^{3+}-\mathrm{Sr}^{+}$curve intersections (see Fig. 5(a)). Due to the competition between the two non-radiative decay pathways and, also, due to the fact that the second absorption is a $d-d$ rather than a MMCT transition, the dopant-to-host electron transfer resulting from this mechanism should be significantly less efficient than that 
resulting from the two-photon MMCT mechanism of the higher energy photoconductivity bands of $\mathrm{CaF}_{2}: \mathrm{Yb}^{2+}$ and $\mathrm{SrF}_{2}: \mathrm{Yb}^{2+}$. This is consistent with and explains the somewhat puzzling experimental photoconductivity of $\mathrm{SrF}_{2}: \mathrm{Yb}^{2+},{ }^{21}$ which is notably less intense at the energies of the first $\mathrm{Yb}^{2+}$ absorption band than at the energies of the second and third absorption bands (see Fig. 7 of Ref. 21). We can recall that the original explanation based on the assumption that all the $4 f^{13} 5 d$ states of $\mathrm{Yb}^{2+}$ lie within the $\mathrm{SrF}_{2}$ conduction band, ${ }^{21}$ which is not supported by the present calculations, required the additional assumption that the coupling with the conduction band was much smaller for the first set of $4 f^{13} 5 d$ states than for the others.

\section{CONCLUSIONS}

$A b$ initio wavefunction based multiconfigurational quantum mechanical calculations of the electronic structure of $\mathrm{Yb} / \mathrm{Ca}$ pairs in $\mathrm{CaF}_{2}$ and $\mathrm{Yb} / \mathrm{Sr}$ pairs in $\mathrm{SrF}_{2}$ allow to locate impurity levels and (local) host levels in a common energy scale in configuration coordinate diagrams that correspond to the dopant-to-host electron transfer reaction: $\mathrm{Yb}^{2+}+\mathrm{Ca}^{2+}$ $\left(\mathrm{Sr}^{2+}\right) \rightarrow \mathrm{Yb}^{3+}+\mathrm{Ca}^{+}\left(\mathrm{Sr}^{+}\right)$involving ground and excited states of the donor-acceptor pairs: $\left[D_{i}, A_{j}\right] \rightarrow\left[D_{k}^{+}, A_{l}^{-}\right]$. Analyses of the $\mathrm{Yb} / \mathrm{Ca}$ and $\mathrm{Yb} / \mathrm{Sr}$ diabatic potential energy surfaces and MMCT configuration coordinate diagrams, obtained from independent embedded cluster calculations, allow to conclude that the photoconductivity of $\mathrm{Yb}^{2+}$-doped $\mathrm{CaF}_{2}$ and $\mathrm{SrF}_{2}$ results from a photoinduced dopant-to-host electron transfer that follows a two-photon mechanism, in which $4 f^{13} 5 d$ excited states of $\mathrm{Yb}^{2+}$ are instrumental. Some of these states are reached by a first photon absorption and some of them absorb a second photon of the same energy, which provokes the $\mathrm{Yb}^{2+}+\mathrm{Ca}^{2+}\left(\mathrm{Sr}^{2+}\right) \rightarrow \mathrm{Yb}^{3+}+\mathrm{Ca}^{+}\left(\mathrm{Sr}^{+}\right)$phototransfer. The $4 f^{13} 5 d$ excited states involved in the photoconductivity process are of two types: the $T_{1 \mathrm{u}}$ states excited by the intra- $\mathrm{Yb}$ first-photon electric dipole allowed absorption $\left[1 A_{1 \mathrm{~g}}, 1 A_{1 \mathrm{~g}}\right]$ $\rightarrow\left[\mathrm{i} T_{1 \mathrm{u}}, 1 A_{1 \mathrm{~g}}\right]$, and the metastable $\left[2 A_{1 \mathrm{u}}, 1 A_{1 \mathrm{~g}}\right]$ and $\left[1 E_{\mathrm{u}}, 1 A_{1 \mathrm{~g}}\right]$ states, which are reached after $\mathrm{i} T_{1 \mathrm{u}} \rightsquigarrow 2 A_{1 \mathrm{u}}$ and $\mathrm{i} T_{1 \mathrm{u}} \rightsquigarrow 1 E_{\mathrm{u}}$ nonradiative decays, lie above a large energy gap, and are the origins of the second photon absorption. In the (second and third) high energy photoconductivity bands of both materials, the second photon is absorbed from $\left[2 A_{1 \mathrm{u}}, 1 A_{1 \mathrm{~g}}\right]$ and induces a $\mathrm{Yb}^{2+}-$ to- $-\mathrm{Ca}^{2+}\left(\mathrm{Yb}^{2+}-\right.$ to- $\left.-\mathrm{Sr}^{2+}\right)$ MMCT and its corresponding photoconductivity. In the (first) low energy, very weak photoconductivity band of $\mathrm{SrF}_{2}: \mathrm{Yb}^{2+}$, the second photon is absorbed from $\left[1 E_{\mathrm{u}}, 1 A_{1 \mathrm{~g}}\right]$ and produces an intra- $\mathrm{Yb}^{2+}$ excitation followed by a non-radiative $\mathrm{Yb}^{2+}$-to- $\mathrm{Sr}^{2+}$ electron transfer and the photoconductivity band. The competition of such nonradiative electron transfer with intra- $\mathrm{Yb}$ non-radiative decays explains the relatively very low photocurrent detected in this case. In $\mathrm{CaF}_{2}: \mathrm{Yb}^{2+}$, the same intra- $\mathrm{Yb}^{2+}$ excitation leads the $\mathrm{Yb}^{2+}-$ $\mathrm{Ca}^{2+}$ pair in an excited state that is below the lowest $\mathrm{Yb}^{3+}$ $\mathrm{Ca}^{+}$state, so that the non-radiative $\mathrm{Yb}^{2+}-$ to- $-\mathrm{Ca}^{2+} \mathrm{MMCT}$ cannot take place and the first photoconductivity band does not exist.

The results of the calculations indicate that only the highest $4 f^{13} 5 d t_{2 g}$ states of $\mathrm{Yb}^{2+}$ in $\mathrm{CaF}_{2}$ and all of the $4 f^{13} 5 d t_{2 g}$ states in $\mathrm{SrF}_{2}$, lie at or above the lowest excited state of the host (or, in other terms, above the bottom of the conduction band); this result does not support the description suggested in the literature that all $4 f^{13} 5 d$ states of $\mathrm{Yb}^{2+}$ in $\mathrm{SrF}_{2}$ and all but the lowest in energy in $\mathrm{CaF}_{2}$ lie in the conduction band of the crystal.

\section{ACKNOWLEDGMENTS}

This work was partly supported by a grant from Ministerio de Economía y Competitividad, Spain (Dirección General de Investigación y Gestión del Plan Nacional de I+D+i, Grant Nos. MAT2011-24586 and MAT2014-54395-P).

${ }^{1}$ C. W. E. van Eijk, Phys. Med. Biol. 47, R85 (2002).

${ }^{2}$ Spectroscopic Properties of Rare Earths in Optical Materials, edited by G. Liu and B. Jacquier (Springer, Berlin, 2005).

${ }^{3}$ Luminescence: From Theory to Applications, edited by C. R. Ronda (WileyVCH, Weinheim, 2007).

${ }^{4}$ M. J. Weber, J. Lumin. 100, 35 (2002)

${ }^{5}$ J. W. Verhoeven, Pure Appl. Chem. 68, 2223 (1996).

${ }^{6}$ R. A. Marcus, Annu. Rev. Phys. Chem. 15, 155 (1964).

${ }^{7}$ G. C. Allen and N. S. Hush, Prog. Inorg. Chem. 8, 357 (1967).

${ }^{8}$ N. S. Hush, Prog. Inorg. Chem. 8, 391 (1967).

${ }^{9}$ M. Robin and P. Day, Adv. Inorg. Chem. Radiochem. 10, 247 (1968).

${ }^{10}$ S. B. Piepho, E. R. Krausz, and P. N. Schatz, J. Am. Chem. Soc. 100, 2996 (1978).

${ }^{11}$ R. J. H. Clark, Chem. Soc. Rev. 13, 219 (1984).

${ }^{12} \mathrm{G}$. Blasse, Struct. Bonding 76, 153 (1991).

${ }^{13}$ C. Wickleder, Z. Naturforsch B 57, 901 (2002).

${ }^{14}$ W. van Schaik, S. Lizzo, W. Smit, and G. Blasse, J. Electrochem. Soc. 140, 216 (1993).

${ }^{15}$ E. Pinel, P. Boutinaud, and R. Mahiou, J. Alloys Compd. 380, 225 (2004).

${ }^{16}$ L. Seijo and Z. Barandiarán, J. Chem. Phys. 141, 214706 (2014).

${ }^{17}$ Z. Barandiarán and L. Seijo, J. Chem. Phys. 141, 234704 (2014).

${ }^{18}$ B. Welber, J. Chem. Phys. 42, 4262 (1965).

${ }^{19}$ D. C. Yu, F. T. Rabouw, W. Q. Boon, T. Kieboom, S. Ye, Q. Y. Zhang, and A. Meijerink, Phys. Rev. B 90, 165126 (2014).

${ }^{20}$ Z. Barandiarán, A. Meijerink, and L. Seijo, Phys. Chem. Chem. Phys. 17, 19874 (2015).

${ }^{21}$ B. Moine, B. Courtois, and C. Pédrini, J. Phys. 50, 2105 (1989).

${ }^{22}$ M. Douglas and N. M. Kroll, Ann. Phys. 82, 89 (1974).

${ }^{23}$ B. A. Hess, Phys. Rev. A 33, 3742 (1986).

${ }^{24}$ B. A. Hess, C. M. Marian, U. Wahlgren, and O. Gropen, Chem. Phys. Lett. 251, 365 (1996).

${ }^{25}$ B. O. Roos, P. R. Taylor, and P. E. M. Siegbahn, Chem. Phys. 48, 157 (1980).

${ }^{26}$ P. E. M. Siegbahn, A. Heiberg, J. Almlöf, and B. O. Roos, J. Chem. Phys. 74, 2384 (1981).

${ }^{27}$ J. Olsen, B. O. Roos, P. Jørgensen, and J. A. Jensen, J. Chem. Phys. 89, 2185 (1988).

${ }^{28}$ P.-A. Malmqvist, A. Rendell, and B. O. Roos, J. Phys. Chem. 94, 5477 (1990).

${ }^{29}$ P.- $\AA^{\circ}$. Malmqvist, K. Pierloot, A. R. Moughal Shahi, C. J. Cramer, and L. Gagliardi, J. Chem. Phys. 128, 204109 (2008).

${ }^{30}$ K. Andersson, P.-A. Malmqvist, B. O. Roos, A. J. Sadlej, and K. Wolinski, J. Phys. Chem. 94, 5483 (1990).

${ }^{31}$ K. Andersson, P.-A. Malmqvist, and B. O. Roos, J. Chem. Phys. 96, 1218 (1992).

${ }^{32}$ A. Zaitsevskii and J.-P. Malrieu, Chem. Phys. Lett. 233, 597 (1995).

${ }^{33}$ J. Finley, P.-A. Malmqvist, B. O. Roos, and L. Serrano-Andrés, Chem. Phys. Lett. 288, 299 (1998).

${ }^{34}$ P. A. Malmqvist, B. O. Roos, and B. Schimmelpfennig, Chem. Phys. Lett. 357, 230 (2002).

${ }^{35}$ Z. Barandiarán and L. Seijo, J. Chem. Phys. 89, 5739 (1988).

${ }^{36} \mathrm{~L}$. Seijo and Z. Barandiarán, in Computational Chemistry: Reviews of Current Trends, edited by J. Leszczyński (World Scientific, Singapore, 1999), Vol. 4, pp. 55-152.

${ }^{37}$ R. McWeeny, Proc. R. Soc. London, Ser. A 253, 242 (1959).

${ }^{38}$ B. O. Roos, V. Veryazov, and P. O. Widmark, Theor. Chem. Acc. 111, 345 (2004).

${ }^{39}$ B. O. Roos, R. Lindh, P. A. Malmqvist, V. Veryazov, and P. O. Widmark, J. Phys. Chem. A 108, 2851 (2005). 
${ }^{40}$ B. O. Roos, R. Lindh, P. A. Malmqvist, V. Veryazov, P. O. Widmarki, and A. C. Borin, J. Phys. Chem. A 112, 11431 (2008).

${ }^{41}$ Z. Barandiarán and L. Seijo, J. Chem. Phys. 138, 074102 (2013).

${ }^{42}$ G. Karlström, R. Lindh, P. A. Malmqvist, B. O. Roos, U. Ryde, V. Veryazov, P. O. Widmark, M. Cossi, B. Schimmelpfennig, P. Neogrady et al., Comput. Mater. Sci. 28, 222 (2003).

${ }^{43}$ Detailed core and embedding AIMP data libraries in electronic format are available from the authors upon request or directly at the address http:// www.uam.es/quimica/aimp/Data/AIMPLibs.html. See also Ref. 42.

${ }^{44}$ See supplementary material at http://dx.doi.org/10.1063/1.4932388 for all calculated vertical electronic transitions from the energy minimum of three donor-acceptor states: $\left[1 A_{1 g}, 1 A_{1 g}\right],\left[1 E_{u}, 1 A_{1 g}\right]$, and $\left[2 A_{1 u}, 1 A_{1 g}\right]$, of $\mathrm{Yb} / \mathrm{Ca}$ pairs in $\mathrm{CaF}_{2}$ and $\mathrm{Yb} / \mathrm{Sr}$ pairs in $\mathrm{SrF}_{2}$. The electronic transitions have been computed as energy differences between the corresponding diabatic potential energy surfaces.

${ }^{45}$ E. Loh, Phys. Rev. 175, 533 (1968).

${ }^{46}$ R. W. G. Wyckoff, Crystal Structures, 2nd ed. (Interscience Publishers, 1982), Vol. 1.

${ }^{47}$ P. P. Feofilov, Opt. Spektrosk. 1, 992 (1956).

${ }^{48}$ A. A. Kaplyanskii and P. P. Feofilov, Opt. Spectrosc. 13, 129 (1962).

${ }^{49}$ E. Loh, Phys. Rev. 184, 348 (1969). 